\title{
UNA METODOLOGÍA CUANTITATIVA DE LA PROGRAMACIÓN AGRÍCOLA
}

\author{
L. M. BASSOCO \\ $\mathrm{Y}$ \\ R. D. Norton
}

\section{ANTECEDENTES}

LA AGRICULTURA es un sector tradicionalmente enigmático para los programadores de política en todas partes del mundo. En países en desarrollo el problema es a menudo más grave, por las metas conflictivas. Se espera que la agricultura soporte diversas cargas: principalmente, satisfacer las necesidades de alimentos, proporcionar empleo y generar divisas. Además la información básica de los países en desarrollo con frecuencia es inadecuada para estimar las respuestas apropiadas a los parámetros del sector.

El enfoque común de la planeación agrícola se orienta a fijar metas de producción de los diferentes productos —en unidades físicas- y a estimar los requerimientos de insumos para estas metas para cada uno de los productos en forma individual. Diversas críticas pueden ser formuladas en contra de este procedimiento. ${ }^{1}$ En primer lugar, si bien las metas de producción pueden satisfacer las necesidades de alimentos y quizás las metas de ingresos de divisas, es probable que no representen el mejor programa para otros propósitos como el empleo. En segundo lugar, aún desde el punto de vista de las necesidades de alimentos, una asignación eficiente de recursos puede requerir que se permita que los precios de algunos productos se eleven, mientras que otros declinen, en términos relativos. Es decir, el sector se enfrenta no a demandas en un punto sino a funciones de demanda. La posición dentro del esquema de demanda debe encontrarse como resultado del problema de la asignación de recursos limitados. En tercer lugar, una planeación adecuada que confronte restricciones de balanza de pagos, puede requerir diversas combinaciones de la oferta interna y de las importaciones de cada producto, lo cual no puede ser manejado en forma adecuada si no se toma en consideración a todos los productos simultáneamente. ${ }^{2}$

${ }^{1}$ Por ejemplo, véase a Mellor (11) p. 382-384 para una crítica al enfoque común de la planeación agrícola.

"Se puede pensar en un procedimiento iterativo en el cual se modifique la producción acumulada respecto a los programas de importación en cada etapa, pero aún esto no permitiría aplicar el impacto de cambiar los patrones de producción sobre el costo de oportunidad de la tierra y otros recursos fijos. 
Una cuarta crítica del enfoque tradicional consiste en que al tratar de agregar todos los requerimientos de insumos de cada uno de los productos, se ignore la sustitución entre productos que puede tener lugar en el lado de la oferta, lo que conduce a una estimación global sesgada de los recursos necesarios. En las zonas de monocultivo esto no significa ningún problema, pero en otras los efectos de sustitución, por el lado de la oferta, pueden ser importantes en los cultivos de ciclo corto.

Por último, una quinta crítica se refiere a que el enfoque tradicional no ofrece un marco para evaluar las variables a nivel sectorial, tales como una función de oferta global, o una elasticidad de sustitución entre factores para el sector agrícola en conjunto.

En éste documento se presenta una metodología de planeación que aun cuando deja sin respuesta algunos problemas difíciles, da soluciones a las cinco críticas planteadas. Para superar limitaciones en la información, el análisis se basa en el uso de datos de sección transversal en relación a costos de producción a nivel de finca, en lugar de series de tiempo de producción total. En este sentido, el sistema se puede concebir como un procedimiento para convertir información microeconómica en conclusiones a nivel macroeconómico o sectorial.

Esta metodología ha sido utilizada recientemente para formular el capítulo del sector agrícola dentro del Programa de Desarrollo Económico y Social 1974-1980. ${ }^{3}$ El instrumento analítico básico es el modelo sectorial CHAC, que describe la oferta y la demanda de 33 cultivos del ciclo corto y los insumos asociados. Una descripción de CHAC ha sido formulada en otra parte. ${ }^{4}$ En este documento sólo se comenta: a) sus modificaciones y usos como instrumento de planeación; y $b$ ) el enfoque de la planeación que ha sido posible a través del modelo. Para ilustrar la propuesta se presentarán abundantes resultados numéricos.

El problema de política como aqui se trata incluye tanto instrumentos tradicionales de política de tipo macroeconómico (tasa de interés, tipo de cambio de las divisas, etc.) como políticas específicas para los productos y los factores. En algunos casos los instrumentos están identificados por región, pero sin llegar al detalle de proyectos específicos de inversión en algunas regiones en particular. Sin embargo el presupuesto de inversión sectorial se toma en cuenta en forma indirecta.

\section{Enfoque del Programa de Desarrollo Económico y SOCIAL DE MÉXICO}

El Programa de Desarrollo Económico y Social de México es insólito en el sentido de que incorpora múltiples medidas concretas de reformas

${ }^{3}$ Este documento fue terminado y distribuido en noviembre de 1973. Contempla un horizonte flexible de planeación, pero la mayor parte se refiere al periodo comprendido hasta 1980.

Véase Duloy y Norton (5) y Bassoco y Rendón (1). 
institucionales y otros programas no cuantificables, muchos de los cuales ya han sido promovidos. Para reducir este documento a límites razonables, no se comentarán estos aspectos sino solamente el marco cuantitativo del Plan. Esto no significa que los aspectos institucionales sean menos importantes, por el contrario, su puesta en ejecución es de suma importancia para que el programa tenga sentido.

La planeación en el contexto de la economía mexicana no significa un control central en el proceso de asignación de recursos, sino más bien el uso coordinado de los instrumentos disponibles para alcanzar los objetivos del plan. Específicamente hay seis categorías principales de instrumentos cuantitativos para influenciar el comportamiento del sector.

a) Programa de inversión en recursos físicos (por ejemplo tierra y obras de regadío;

b) Programas de inversión en investigación y extensión;

c) Políticas de precios de productos y factores;

d) Políticas de comercio (tarifas, incentivos a la exportación);

e) En algunos casos la asignación de factores entre cosechas o entre regiones (por ejemplo la asignación del crédito a corto plazo por cultivo, en algunas regiones); y

f) Políticas de tenencia de la tierra (por ejemplo la determinación del tamaño de la propiedad agrícola).

Además, la tasa de crecimiento global del PIB, que puede estar influenciada por la política fiscal, monetaria y otras políticas, afecta el comportamiento del sector a través de cambios en las funciones de demanda para los productos agrícolas.

Cada uno de estos instrumentos de política y la tasa de crecimiento del PIB, es representada por un conjunto de parámetros en el modelo. Para el Programa de Desarrollo, los instrumentos de política fueron analizados mediante el procedimiento de resolver CHAC bajo supuestos alternativos de política, atendiendo al valor de los parámetros. Se obtuvieron soluciones para dos puntos del tiempo (1968 y 1976) y la tasa de crecimiento de cada variable de interés fue calculada ex-post. Por lo tanto, el análisis de planeación realizado puede ser considerado como un ejercicio dentro de la estática comparada. Los diferentes supuestos de política se reflejaron en valores alternativos de los parámetros para 1976. En el caso de las políticas cuyo impacto es acumulativo en el tiempo, se establecieron hipótesis en forma de tasas anuales de cambio y se proyectaron para estimar los valores para el año de 1976. El modelo representa una simulación de los diferentes impactos de estas políticas hipotéticas. En este sentido, las alternativas posibles de paquetes de políticas, pueden ser evaluadas en términos de sus múltiples consecuencias, antes de que sea realizada la selección final. Por supuesto que otras consideraciones entran en las decisiones de política, pero esta simulación de las probables con- 
secuencias es una ayuda importante en el proceso de decisión. En la agricultura, con todas sus interrelaciones tanto en el lado de la oferta, como en la demanda, la realización de una simulación apegada a la realidad requiere de un modelo bien detallado.

Dado que CHAC está muy desagregado en términos de cultivos, tecnologías de producción y regiones productoras, ha sido posible señalar las consecuencias potenciales de política hipotéticas con un nivel razonable de especificación, en lo cual el juicio de los agrónomos y otros especialistas es conveniente. Esto ha sido útil tanto para la comprobación de la validez $^{5}$ del modelo como para la interpretación de las proyecciones.

Antes de continuar con los detalles del modelo y con los resultados mismos, se presenta una ilu'stración de la naturaleza de las proyecciones de CHAC para un cultivo individual (véase la gráfica 1). Se supone que el período base de equilibrio está dado por $e_{1}$, con precio $p_{1}$ y cantidad vendida $q_{1}$. Al tomar en cuenta el crecimiento de la población, el crecimiento del ingreso por habitante y las elasticidades ingreso de la demanda, se puede decir que la curva de demanda interna cambia a $D_{2}$ al final del período de planeación. Si el esfuerzo combinado del cambio tecnológico y del crecimiento en la disponibilidad de los recursos agrícolas, da como resultado un cambio más lento en la función de oferta, ésto se puede representar como la curva $S_{2}$ al final del horizonte de planeación. En este caso la nueva cantidad de equilibrio es $q_{2}$ y el nuevo precio es $p_{2}>p_{1}$. Por otra parte una expansión más rápida de la oferta puede proporcionar la curva $S_{3}$, con una cantidad de equilibrio mayor $q_{3}$ y un precio $p_{3}<p_{1}$.

El método tradicional de establecer metas fijas de producción, consiste en forzar que la oferta sea igual a la cantidad $q^{*}$, dada por la función de demanda $D_{3}$ que es inelástica con respecto al precio. Como este procedimiento no toma en cuenta los precios, el costo marginal de la oferta se eleva hasta $p_{4}$ en el caso que la función de oferta sea $S_{2}$, y cae hasta $p_{5}$ en el caso que la función de oferta sea $S_{3}$.

Si en verdad se desea alcanzar la cantidad $q^{*}$, se requiere de un sistema de impuestos y subsidios para inducir al mercado a alcanzar la cantidad de equilibrio. En el caso de la función de oferta $S_{2}$ se requeriría un subsidio unitario a los productores que iguale en valor la distancia $a b$, y en caso de la función de oferta $S_{3}$, se necesitaría un impuesto a los productores igual a la distancia $b d$. Es claro que habría pérdidas en bienestar asociadas al hecho de imponer como meta la cantidad $q^{*}$; lo cual está medido por el área $a e_{2} b$ y $b e_{3} d$ en caso de dos funciones de oferta respectivamente. Las pérdidas de bienestar implican pérdidas en eficiencia productiva así como pérdidas en el bienestar de los consumidores; y eso hace más difícil alcanzar las metas de producción en otros productos. De lo anterior se desprende que establecer metas fijas en la cantidad de todos los cultivos, implica un nivel de producción total menor

\footnotetext{
${ }^{5}$ Para varias pruebas respecto a la validez del modelo véase a Bassoco et al (2) y Duloy y Norton (6).
} 


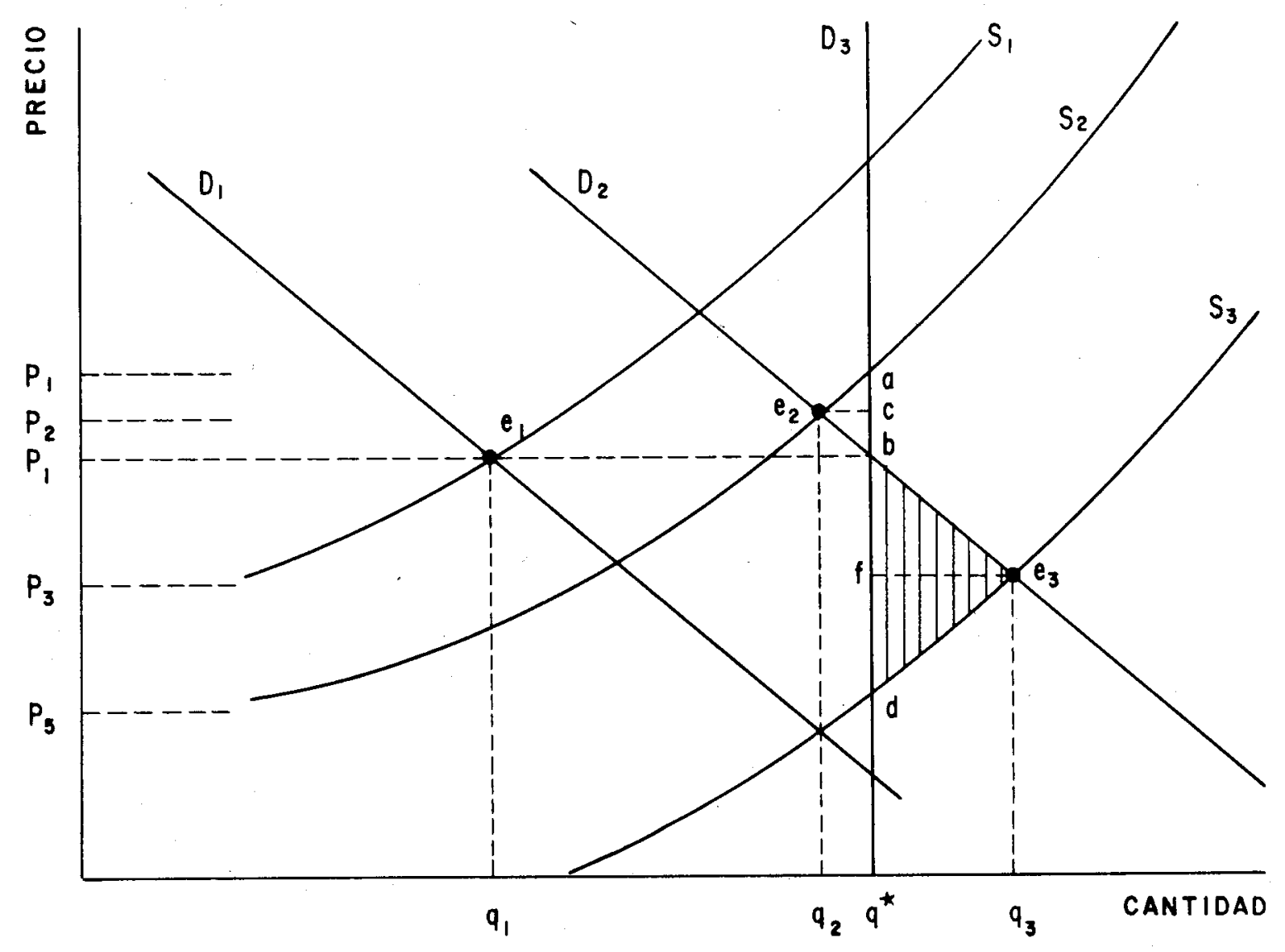


que al permitir el equilibrio entre oferta y demanda sea alcanzado para cada cultivo. ${ }^{6}$

Esta afirmación se refiere en particular, al caso en el cual las metas de producción son establecidas solamente con referencia a las elasticidades ingreso de demanda y a cambios en los factores que determinan la demanda, como es la práctica común. Si las funciones de oferta estimadas y proyectadas correctamente junto con la demanda, y si las funciones de demanda respecto a los precios fueran conocidas, las metas podrían ser alcanzadas de acuerdo con las cantidades de equilibrio; pero en este caso el problema de planeación estaría resuelto y no habría necesidad de establecer metas fijas que permitan estimar y agregar los requerimientos de insumos productivos.

De hecho, como ya se mencionó antes, las funciones de oferta agrícola son bien complejas e incluyen múltiples productos. La información disponible para las series de tiempo, con frecuencia no ofrece suficientes grados de libertad para permitir una estimación econométrica adecuada de los parámetros de la función de producción con varios productos y varios factores. Por lo tanto, la ventaja práctica significativa de los modelos de "análisis de procesos" consiste en que las alternativas tecnológicas pueden incluir implícitamente funcionès de oferta de múltiples productos de orden elevado.

Por último, se podría señalar que las prácticas tradicionales de planeación no se refieren tanto a la imposición de metas físicas de producción como a la formulación de proyecciones. En este caso, las pérdidas en bienestar no entran en el panorama pero constituyen errores de predicción en relación con las predicciones por medio del equilibrio cambiante. En la gráfica 1 tales errores de pronóstico expresados en términos de cantidad son: $q_{2}-q^{*}$ y $q^{*}-q_{3}$.

\section{CHAC. UN PANORAMA}

Los principales elementos de cHAC pueden ser sintetizados de la siguiente manera:

\section{Cobertura sectorial}

Incluye todas las fuentes de oferta (interna e importaciones) y todas las fuentes de demanda (interna y exportaciones) para los 33 cultivos de ciclo corto analizados. No incluye ganadería, silvicultura y cultivos de ciclo largo.

\section{Interdependencia por el lado de la oferta}

La oferta se describe como un conjunto de alternativas tecnológicas para cada una de las veinte regiones. Se incluyen alternativas en la me-

${ }^{\circ}$ Más adelante se comparan las proyecciones de equilibrio de CHAC con las proyecciones que resultan de utilizar sólo elasticidades ingreso de la demanda. 
canización, en las fechas de siembra, en la fertilización y en el regadío. El total de alternativas tecnológicas para 33 cultivos y 20 submodelos es 2348 . Debido al hecho de que cada submodelo contiene un gran número de cultivos que compiten por el uso de los mismos recursos naturales locales (tierra, agua y mano de obra familiar), las elasticidades cruzadas implícitas de la oferta, tienen por lo general un valor positivo. Esta es la forma en que el análisis de procesos capta la fuerte interdependencia que existe dentro del conjunto de la oferta. Además de recursos locales, los otros insumos agrícolas son jornaleros, insumos químicos, semillas mejoradas, servicios de maquinaria agrícola, de tracción animal, crédito a corto plazo y costos misceláneos. La tierra, el agua y la mano obra están considerados a nivel mensual. Para el tratamiento de la mano de obra, como se explica más adelante, los veinte submodelos están agrupados en cuatro regiones principales.

\section{Interdependencia en la demanda}

Como se sèñaló antes, en CHAC se incorporaron funciones de demanda interna, elástica respecto al precio. Cuando se formulan proyeecciones, se utilizan elasticidades ingreso de la demanda, para hacer los cambios necesarios en las funciones estáticas de demanda. Esta estructura permite variar las proporciones de cultivos dentro de la producción total con variaciones correspodientes en los precios relativos y cuantificar la sustitución indirecta en la demanda. Además, se especificaron grupos de cultivos dentro de los cuales puede tener lugar una sustitución limitada, a una tasa marginal de sustitución constante. Por falta de información más precisa, la demanda de exportación está especificada generalmente como perfectamente elástica hasta un límite superior. ${ }^{7}$ La interdepencia tanto en la oferta como en la demanda, es un aspecto importante del sector agrícola y su incorporación en el modelo ha ayudado de manera considerable respecto al realismo de los resultados.

\section{Simulación del equilibrio del mercado}

La incorporación de estructuras de demanda permite identificar formas alternativas de mercado, ya sea competitivo, monopólico o regímenes semimonopólicos de control de oferta. Para el conjunto de las soluciones de CHAC, se supuso la estructura competitiva del mercado, dado que con algunas posibles excepciones en frutas y hortalizas, ningún productor $\mathrm{o}$ asociación de productores pueden influenciar el precio de mercado a través de sus decisiones de producción.

Las características de optimización del modelo, no son utilizadas en un sentido normativo para maximizar un conjunto de objetivos, sino más

${ }^{7}$ Desde el punto de vista de la construcción de modelos, no hay obstáculos para especificar funciones de demanda para las exportaciones. Sólo se requiere más información analítica sobre los mercados externos. 
bien en un sentido descriptivo, para simular el comportamiento del mercado competitivo. Esto se alcanza mediante la maximización de la suma de los excedentes Marshallianos en cada mercado de productos. ${ }^{8}$ También se han hecho modificaciones al supuesto de competencia pura para el caso de algunos productores en áreas de temporal, en las cuales la participación en el mercado está menos extendida. Esto se discute más adelante.

\section{Elementos de dualismo}

Los conceptos de dualismo están contenidos en cHAC en el conjunto de alternativas tecnológicas y en los parámetros de la participación en el mercado. Una explicación para las bajas elasticidades de la oferta agrícola que a menudo tienen los productores tradicionales, es que estos productores tienen que considerar menos alternativas de producción al hacer sus decisiones para la siembra. Los agricultores que disponen de riego y que tienen tierra suficiente que les permita afrontar algunos riesgos, pueden contemplar en sus normas de producción, una amplia variedad de granos, hortalizas, oleaginosas, frutas y otros cultivos similares en rendimiento por hectáreas. Por lo tanto, un cambio pequeño en los precios relativos de las cosechas es más probable que los induzca a cambios en los patrones de producción que si estuvieran en el caso de un agricultor que tienen menores alternativas de producción. En CHAC, las áreas de temporal ofrecen menos alternativas y tecnologías de producción que las zonas de riego.

La segunda forma en la cual los productores tradicionales están diferenciados en el modelo, es por la especificación de las restricciones de autoconsumo. Muchos productores tienden a satisfacer las necesidades de consumo de alimentos básicos de sus familias (maíz) antes de venderlo o producir otro bien. Hay varias explicaciones posibles, no todas ellas estrictamente económicas, que pueden ser aducidas para este comportamiento; pero para el modelo se estableció un supuesto sencillo para explicar el comportamiento observado: si un agricultor satisface los requerimientos de alimentos de su familia a través de compras de maíz en el mercado durante el año, el precio promedio por kilogramo que él paga, será más alto que el precio que podría obtener por su propia cosecha de maíz al tiempo de la cosecha. Este diferencial de precio surge tanto del margen normal de compra-venta (quizá exagerado por imperfecciones del mercado) como de cambios estacionales en el precio. En el modelo se supone que este diferencial es pagado cuando: un agricultor no dedica a la producción de maíz suficiente tierra para satisfacer las necesidades de consumo. En las soluciones del modelo, éste diferencial probó alentar la producción para autoconsumo, permitiendo la

\footnotetext{
s Para una exposición completa de la estructura de demanda de CHAC y de sus propiedades, véase Duloy y Norton (7).
} 
diversificación de cultivos solamente después de que el autoconsumo estuvo satisfecho.

\section{Funciones de oferta de mano de obra}

La mano de obra en CHAC está especificada en tres categorías básicas: 1) agricultores y trabajadores familiares; 2) jornaleros y; 3) tractoristas. La disponibilidad de agricultores está dividida en 20 grupos en que cada uno corresponde a un modelo regional por el lado de la producción. Se supone que los agricultores con tierra de riego no migran o trabajan en otros predios en el corto plazo, pero que en cambio los agricultores de temporal están disponibles para contratarse como jornaleros en los meses que no son críticos. $^{9}$ La disponibilidad de jornaleros está dividida en cuatro regiones y la migración interregional puede ocurrir en el modelo si los jornaleros de una región dada están empleados plenamente cuando menos durante un mes. Por lo tanto, la utilización de jornaleros y agricuitores en las áreas de temporal se considera por mes. La utilización de agricultores en los submodelos de riego está definida en términos anuales: un agricultor se compromete (él mismo) a vigilar su predio agrícola durante todo el año. Se supone que los tractoristas están disponibles ilimitadamente al salario corriente y por lo tanto no se impone ninguna restricción en la cantidad. En el mundo real constituyen una pequeña fracción de la fuerza de trabajo y nunca se ha mencionado una limitación en su disponibilidad, como un obstáculo para el desarrollo agrícola.

El salario de los jornaleros se establece a los niveles corrientes de mercado en cada una de las cuatro regiones: la región noroeste tiene un salario cerca del doble de la región sur, lo que refleja el ritmo lento al cual se ajustan los salarios regionales. La mano de obra de los agricultores está valuada mensualmente a un "salario de garantía" que es mayor que cero, pero menor que el salario de los jornaleros. En sentido restringido, el salario de garantía puede ser considerado como una medida de la desutilidad del trabajo; es decir, es la productividad mínima a la cual los agricultores realizarían labores adicionales en sus predios. Se ha observado que en algunas ocasiones los productores no adoptan nuevas técnicas que ofrezcan una productividad adicional muy pequeña por unidad de trabajo adicional. En otras palabras, a un salario de cero, la oferta de mano de obra es cero. El tiempo de las personas es demasiado valioso (incluídas actividades no económicas) para desperdiciarlo en

${ }^{9}$ Este supuesto se desprende del ciclo de trabajo menos intenso que se observa en los predios de temporal, en donde no es posible realizar los cultivos más intensivos en el uso de mano de obra, ni el doble cultivo. Sin duda que hay excepciones: los productores de predios pequeños con riego pueden trabajar fuera del predio estacionalmente y los productores de predios grandes, en áreas de temporal, pueden permanecer en sus explotaciones durante todo el año, pero en conjunto el supuesto describe el grado actual de moviliddad de la mano de obra. 
trabajo no productivo. Por otro lado, es claro que los agricultores realizan en sus predios algunas labores de baja productividad durante varios meses, al tener la certidumbre que al tiempo de la cosecha su ingreso crecerá a una tasa elevada. Esto significa que a lo largo de un año los agricultores percibirán no solamente la suma del salario de garantía mensual, sino también la renta económica que proviene de su tierra, agua, mano de obra y de su capacidad como empresario. De hecho en CHAC los salarios de garantía representan generalmente de una tercera hasta una quinta parte del ingreso total. La pregunta empírica planteada se relaciona con el nivel adecuado del salario de garantía. También se realizaron diversas simulaciones con el modelo sectorial y con varios submodelos individuales, con diferentes supuestos respecto a la estimación del salario de garantía, para observar cual cifra proporcionaba las pautas más adecuadas de cultivo y de utilización de mano de obra. Para las zonas de riego los resultados correctos fueron siempre alrededor de $40 \%$ a $50 \%$ respecto al salario de los jornaleros; los valores en los intervalos de 0 a $30 \%$ y $60 \%$ a $100 \%$ proporcionaron resultados que se distorsionaban bastante de la realidad. Para las zonas de temporal, los valores adecuados respecto al salario de garantía parecen ser menores: alrededor del $30 \%$ al $40 \%$ del salario del mercado. Por lo tanto, para las soluciones dedicadas a la programación del sector se adoptaron valores en estos intervalos.

\section{Estática comparativa}

CHAC es un modelo anual que puede ser resuelto para cualquier ciclo agrícola. Las pruebas de validez del modelo fueron realizadas para el año de $1968,{ }^{10}$ estableciendo como restricciones la disponibilidad de recursos para ese año. Posteriormente se obtuvieron soluciones para 1976, bajo supuestos alternativos en los siguientes parámetros:

i) En la tasa del crecimiento de la tierra cultivable, en la disponibilidad de riego y en la fuerza de trabajo.

ii) En la tasa de cambio de los rendimientos por hectárea en todos los cultivos.

iii) En la tasa de crecimiento del PIB (que determina el grado del desplazamiento en la función de demanda).

iv) En la tasa de cambio de los límites superiores de las exportaciones agrícolas (que no son necesariamente iguales a los niveles de las exportaciones de las soluciones), para reflejar las condiciones cambiantes del mercado internacional.

Para cada solución a 1976 , se calcularon las tasas de cambio 1968 a 1976 las cuales se presentan más adelante. Estas soluciones constitu-

${ }^{10}$ En el caso de los parámetros aleatorios, tales como precios y rendimientos unitarios, se utilizó el promedio de los años: 1967, 1968 y 1969. 
yen el conjunto de los resultados obtenidos para la planeación del sector. Permiten evaluar la sensibilidad en el comportamiento dinámico de diversas variables, respecto a políticas que han sido diseñadas para influenciar algunos parámetros como la disponibilidad de tierra y agua, la tasa de crecimiento de los rendimientos y la apertura de nuevos mercados de exportación. También se realizaron otras soluciones adicionales para probar la sensibilidad del modelo en un sentido estático para el año de 1968. Para cada una de ellas se formularon isocuantas para este año con el objeto de medir la sustitución entre capital y mano de obra, bajo diversas relaciones de precios relativos de los factores. Estos resultados también fueron utilizados para el proceso de planeación y evaluación de medidas alternativas de política.

\section{Principales resultados macroeconómicos}

\section{La dinámica de las variables básicas macro-económicas}

En el planteamiento respecto a la estática comparativa, se mencionó que se incorporaron cuatro tipos de información exógena, para formular las proyeecciones con CHAC. En términos de números exactos, se hicieron los siguientes supuestos, para establecer el "caso básico" en 1976:

i) La disponibilidad de riego y de tierra cultivable, aumenta al $2 \%$ anual, de 1968 a 1976. Esto se refleja en un incremento de $2 \%$ anual en el número de familias campesinas. ${ }^{11}$

ii) Los rendimientos agrícolas por hectárea aumentan (en porciento) al siguiente ritmo anual: ${ }^{12}$

\begin{tabular}{|c|c|c|c|}
\hline arroz & 2.0 & ajo & 3.5 \\
\hline ajonjolí & 0.5 & algodón & 3.0 \\
\hline alfalfa & 1.0 & caña azúcar & 1.0 \\
\hline avena & 1.2 & cártamo & 1.1 \\
\hline cacahuate & 0 & cebada & 1.5 \\
\hline chile & 2.4 & camote & 2.3 \\
\hline cebolla & 2.3 & fresa & 8.0 \\
\hline frijol & 2.3 & garbanzo & 0 \\
\hline haba & 0 & jitomate & 4.0 \\
\hline linaza & 1.1 & maíz & 2.0 \\
\hline melón & 3.5 & papa & 4.0 \\
\hline
\end{tabular}




$\begin{array}{lrll}\text { pepino } & 4.0 & \text { piña } & 1.0 \\ \text { sandía } & 2.0 & \text { sorgo } & 1.5 \\ \text { soya } & 0 & \text { tabaco } & 2.3 \\ \text { trigo } & 4.0 & & \end{array}$

iii) El PIB crece al $8 \%$ anual, así como el ingreso disponible.

iv) Los límites superiores en las exportaciones crecen al ritmo anual siguiente:

$\begin{array}{lrlr}\text { ajo } & 4.8 & \text { ajonjolí } & 14.6 \\ \text { algodón } & 4.1 & \text { cacahuate } & 5.1 \\ \text { caña azúcar } & 0.9 & \text { cártamo } & 30.0 \\ \text { chile verde } & 17.3 & \text { chile seco } & 2.4 \\ \text { cebolla } & 8.0 & \text { fresa } & 5.3 \\ \text { frijol } & 3.9 & \text { garbanzo } & 34.0 \\ \text { haba } & 58.0 & \text { jitomate } & 6.0 \\ \text { melón } & 3.9 & \text { papa } & 65.0 \\ \text { pepino } & 4.3 & \text { piña } & 2.0 \\ \text { sandía } & 13.6 & \text { tabaco } & 16.1 \\ \text { trigo } & 16.1 & & \end{array}$

Los resultados macroeconómicos que se presentan en el cuadro 1, demuestran en primer lugar que la diferencia entre $7 \%$ y $8 \%$ de crecimiento en el PIB, es importante para el sector agrícola. Para evitar incrementos en las importaciones, ${ }^{13}$ la producción del sector debe crecer al $4.7 \%$ en un caso y al $5.4 \%$ en el otro. Aún con este incremento en la producción, ésta no se está manteniendo de acuerdo a los aumentos en la demanda, como se puede apreciar por los incrementos en los precios agrícolas proyectados'en relación al nivel general de precios en la economía: $1.5 \%$ anual en el caso de $7 \%$ de crecimiento en el PIB y $2 \%$ anual en el caso de $8 \%$.

Estos ritmos de crecimiento en los precios relativos constituyen algunas de las medidas acerca de la suficiencia del programa de desarrollo del sector agrícola, en el contexto de un programa nacional. Como se señaló anteriormente, están basados en cierto ritmo de incremento de la tierra cultivable, del agua de regadío y de los rendimientos por hectárea, los cuales están determinados en parte por la magnitud y composición del programa de inversión pública agrícola. La implicación de este resultado es clara: las tasas supuestas de crecimiento en la disponibilidad de recursos no son suficientes para satisfacer las necesidades de expansión de la producción agrícola. ${ }^{14} \mathrm{Si}$ bien los ritmos de cambio en los precios

${ }_{13}$ Como un supuesto, los niveles de importación se mantuvieron constantes en 1968 y en 1976; pero se pueden diseñar soluciones que permitan cambios en la estructura de las importaciones.

14 De hecho, en este momento los programas de inversión pública en México, están ampliando la disponibilidad de recursos agrícolas a un ritmo ligeramente más rápido. Es conveniente realizar más soluciones para examinar la situación actual. 


\section{Cuadro 1}

MODELO CHAC: PRINCIPALES RESUlTADOS MACROECONÓMICOS (millones de pesos de 1968)

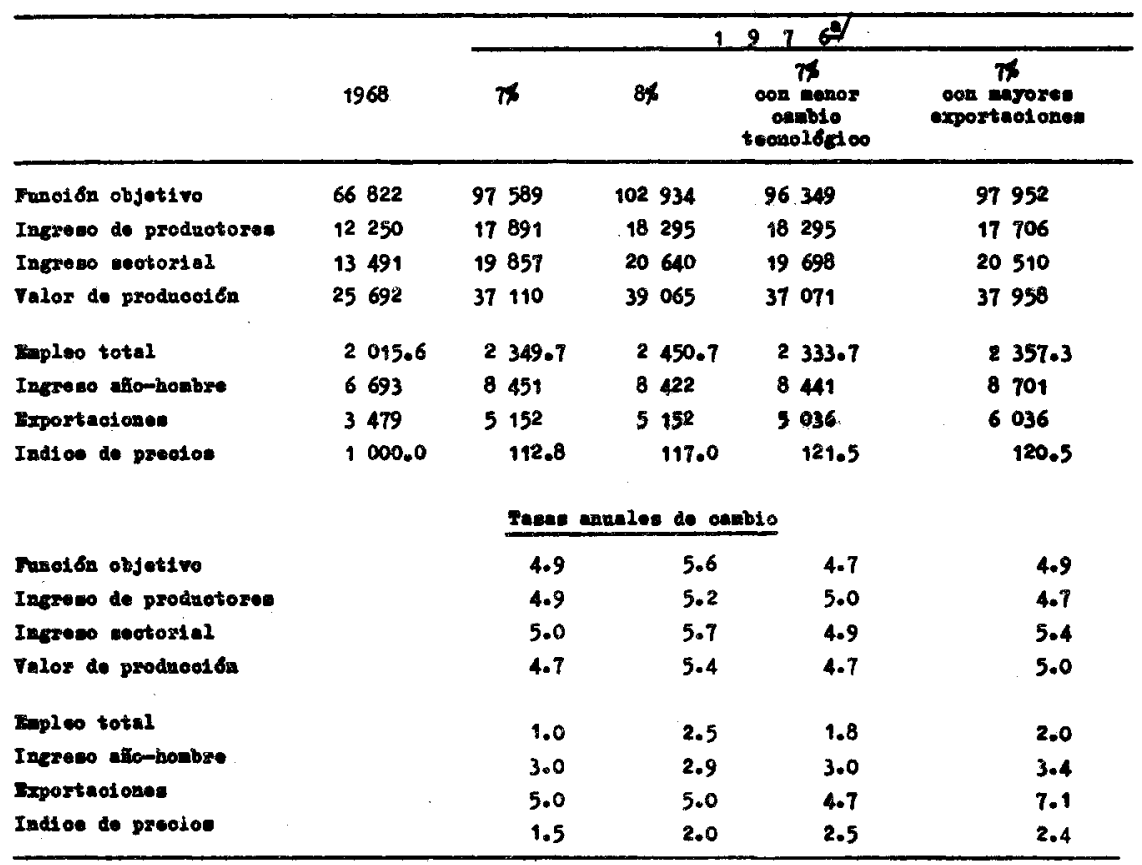

a Con diferentes supuestos de crecimiento en el $P I B$

relativos son indicadores útiles, hay que tener cuidado en interpretar los precios endógenos de CHAC a nivel agregado sectorial. Estos precios reflejan cambios en los precios agrícolas, en relación al resto de los precios de la economía; pero como los precios agrícolas son uno de los principales determinantes del nivel general de precios y como los efectos secundarios no están incluidos en el análisis, hay por lo tanto una falta de integración en CHAC que no puede ser superada sin aumentar el modelo hasta un modelo global de la economía. Es posible sin embargo usar los precios que surgen de las soluciones de CHAC de las dos siguientes maneras:

a) El índice de precios para el sector en su conjunto puede ser comparado entre una y otra solución para ver que tan inflacionario es cada proyecto alternativo, en relación a otros programas;

b) Los precios de los productos individuales en cada solución de CHAC, pueden ser analizados para apreciar cuales productos son probablemente los más (o los menos) estables en precios.

Otro aspecto interesante de los resultados macroeconómicos se refiere 
al empleo. Medido con el total de años-hombre, el empleo se eleva del $1.9 \%$ al $2.5 \%$ anual en varias de las soluciones. Dado que la fuerza de trabajo del sector crece a más de $3.0 \%$ anual, esto implica una migración rural-urbana continua, a un ritmo significativo. Al comparar estos ritmos de crecimiento del empleo con los ritmos de crecimiento de la producción, se aprecia que la "elasticidad empleo ${ }^{15}$ de la producción agrícola", es de alrededor de 0.40 (de 0.38 a 0.46 en las cuatro soluciones).

En términos de años-hombre, en vez de elasticidades, una tasa de crecimiento de la producción agrícola del $4.7 \%$ crea alrededor de 55000 años-hombre de empleo y $5.4 \%$ de crecimiento en la producción genera alrededor de 73000 años-hombre ${ }^{16}$ dados los precios actuales de capital y mano de obra. El incremento de la tasa de crecimiento de las exportaciones (en las proporciones supuestas para cada cultivo) del $5.0 \%$ al $7.1 \%$, agrega alrededor de 3000 años-hombre por año.

En términos de trabajo, los resultados son diferentes. La fuerza de trabajo del sector es una mezcla de jornaleros que pueden trabajar tan sólo un mes al año y agricultores que pueden trabajar hasta doce meses al año. El impacto sobre los trabajos de varios tipos, se aprecia mejor a través de los cambios en las pautas mensuales de empleo lo cual se presenta en una sección posterior.

\section{Curvas de oferta sectorial}

La respuesta global del sector puede ser medida de varias maneras. En primer lugar está la sencilla "elasticidad" de la producción del sector con respecto al PIB. ${ }^{17}$ Los resultados del cuadro 1 muestran que esta elasticidad es del orden de 0.67 a 0.71 para un ritmo de crecimiento del PIB entre $7 \%$ y $8 \%$. El valor más alto de la elasticidad corresponde al caso de un ritmo acelerado en el crecimiento de las exportaciones. Sin embargo, este concepto no es lo mismo que la elasticidad de la oferta. A través de este concepto es posible medir la respuesta agregada del cambio en el equilibrio entre la oferta y la demanda, para todos los cultivos del sector.

Una versión de la elasticidad de la oferta agregada puede ser medida a través de estos resultados. La gráfica 2 ilustra el procedimiento. La curva $D^{68}$ es la curva de demanda elástica al precio para el año base

${ }^{15}$ Definida como la tasa de crecimiento anual en el empleo, dividida por la tasa de crecimiento anual en la producción del sector, en una solución dada.

${ }^{18}$ Para estos cálculos se supone: a) que la fuerza de trabajo en el sector en la actualidad es de 7000000 de personas aproximadamente; y $b$ ) que el trabajador medio en el sactor (incluidos aquéllos que t:abajan tiempo completo, tiempo parcial o no trabajan), trabaja cinco meses al año.

${ }^{17}$ La elasticidad se mide aquí como el porciento de cambio en la producción del sector, dividido por el porciento de cambio en el PIB. Hay que destacar que los valores pueden ser diferentes fuera del rango de $7 \%$ a $8 \%$ de crecimiento del PIB. 
1968 y las curvas $D^{76-1}$ y $D^{76-2}$ son las curvas correspondientes a 1976 , de acuerdo al $7 \%$ y al $8 \%$ de crecimiento anual en el PIB. En CHAC estas curvas han sido desplazadas en una proporción que está determinada, tanto por la tasa de crecimiento del PIB, como por la magnitud de la elasticidad ingreso de la demanda. ${ }^{18}$ Por tanto, el momento del cambio es diferente para cada producto. La gráfica 2 se refiere al caso de un sólo producto agregado para propósitos ilustrativos. La curva de oferta implícita en CHAC (que realmente no es lineal en el modelo) está representada por $S^{68}$ para 1968 y $S^{76}$ para el año 1976 . En la gráfica se puede apreciar que la elasticidad arco de la oferta entre el punto $a$ y el $b$ se calcula de la siguiente manera:

$$
E=\frac{\left(q_{2}-q_{1}\right) /\left(q_{2}+q_{1}\right)}{\left(p_{2}-p_{1}\right) /\left(p_{2}+p_{1}\right)}
$$

Dado que el modelo proporciona estimaciones tanto de precios como de cantidades, el cálculo es directo usando los índices de producción y precios del cuadro 1 . Los casos que se refieren al $7 \%$ y $8 \%$ de crecimiento para 1976, se usaron porque en conjunto identifican diferentes puntos en la misma curva de oferta. Se tiene por ejemplo que no es posible utilizar pares de puntos definidos para las soluciones para 1968 y 1976, porque se refieren a diferentes funciones de oferta. De igual modo, los casos de mayor o menor cambio tecnológico no pueden ser usados con este propósito.

Si se considera $7 \%$ y $8 \%$ de crecimiento en el PIB, los cálculos proporcionan una elasticidad agregada de $1.383^{19}$ ¿cómo se debe interpretar esta cifra? En primer lugar en un sentido representa una elasticidad de oferta a largo plazo, puesto que se refiere al comportamiento entre dos puntos de equilibrio, después de que todos los ajustes en el proceso han sido realizados.

Sin embargo, en otro sentido es un concepto a corto plazo, porque no incluye inversiones para aumentar la disponibilidad de recursos del sector (tierra y agua). Este aumento se toma en cuenta en el desplazamiento de la función de oferta de $S^{68}$ a $S^{76}$. Por lo tanto, es posible denominar a la elasticidad calculada con los resultados de CHAC como una "elasticidad de equilibrio a corto plazo".

${ }^{18}$ En la versión original de CHAC, las curvas de demanda fueron desplazadas en un sentido paralelo; pero como en chac las curvas de demanda han sido linealizadas, este procedimiento origina un cambio en el valor de la elasticidad en un punto a un mismo nivel de precios. Por tanto, en la nueva versión de cHac, con el programa generador de matrices, éste actúa como un pivote en el punto en el cual la curva de demanda intersecta el eje verrtical, manteniendo constante el valor de la elasticidad. Estamos agradecidos con Hunt Howell por esta mejora en el programa generador de matrices.

${ }_{10}$ Como referencia, en CHAC la elasticidad ingreso de la demanda ponderada (incluyendo todos los productos) es +0.545 , al utilizar como ponderaciones las cantidades producidas en la solución del modelo para 1968. 
Gráfica 2

Procedimiento PaRa Medir la Respuesta sectorial de la oferta

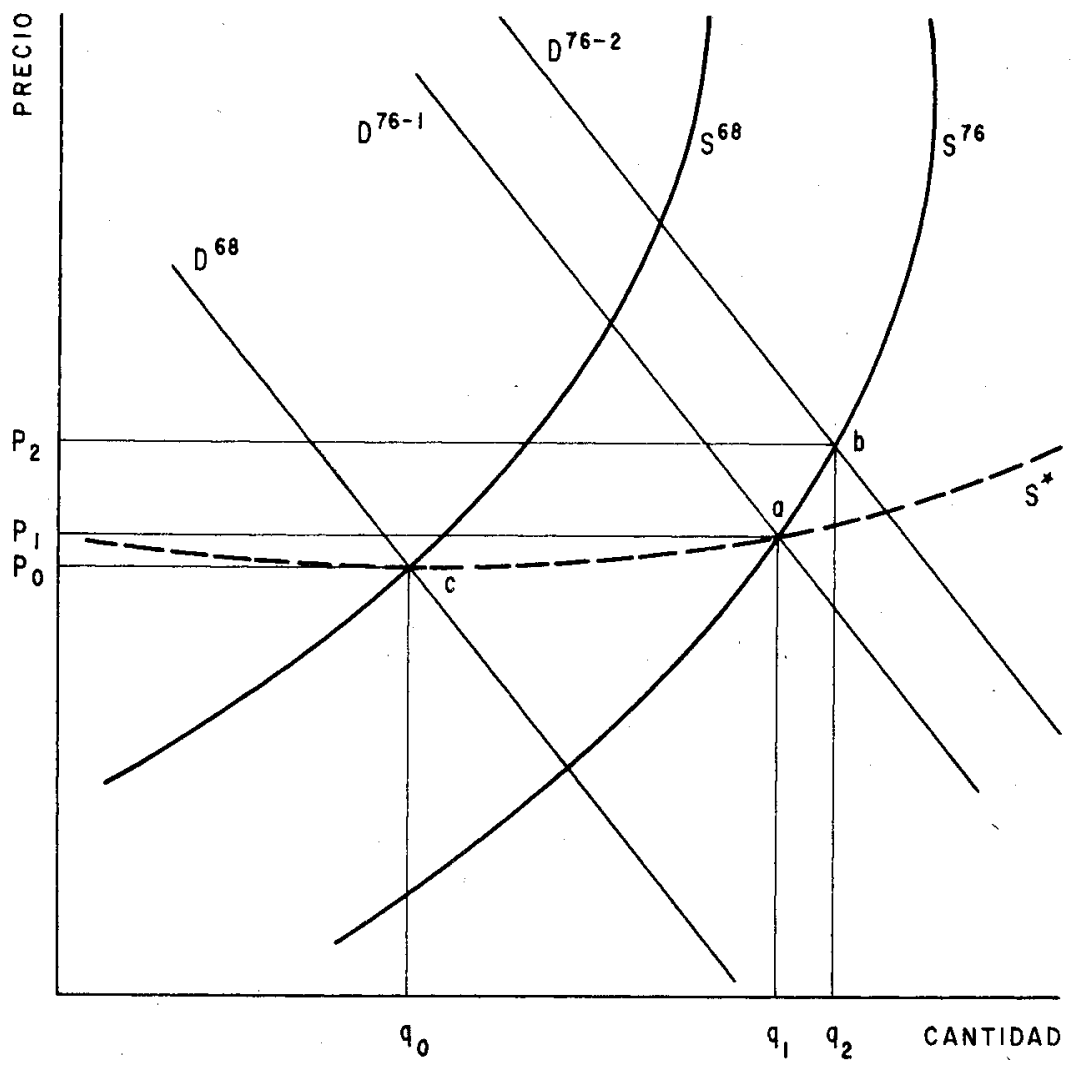

Además, como se mencionó antes, se refiere sólo a la oferta de los cultivos de ciclo corto. Es evidente que esta cifra sería más pequeña en los siguientes casos: a) si se tratara de cultivos perennes, y; b) si fuera un concepto puro de elasticidad a corto plazo (no equilibrio). Al observar la elasticidad con este enfoque, la magnitud parece razonable, a la luz de los estudios existentes de otros países. ${ }^{20}$

En forma alternativa es posible redefinir la función de oferta como una función en equilibrio a largo plazo, que incluye los efectos de las inversiones fijas y los cambios en rendimiento a lo largo del tiempo. Esta sería la curva $S^{*}$ en la gráfica 2 , que pasa a través de los puntos c y $a$. Si se utiliza la misma regla para la medición, la elasticidad arco

20 Para un planteamiento amplio tanto de los procedimientos de la estimación econométrica como de los resutados numéricos, véase Jere Behrman (3). Las elasticidades de oferta puras a corto plazo, son por lo general alrededor de la mitad del valor calculado con los resultados de CHAC. 
a largo plazo (entre los puntos $c$ y a) se calcula con un valor de $+3.030 .{ }^{21}$ Se puede preguntar cuál es la contribución del progreso tecnológico (cambio en los rendimientos por hectáreas) en este valor. Aquí es necesario tratar explícitamente los casos de ritmos diferentes de progreso tecnológicos. Con un ritmo más lento de progreso, la elasticidad arco de equilibrio a largo plazo se calcula en +1.865 (casos 4 y 1 en el cuadro 1). En otras palabras, al reducir el ritmo de crecimiento en los rendimientos por hectárea de 2 a $1 \%$ anual en promedio para todos los cultivos, la elasticidad de la oferta se reduce cerca de $40 \%$. Este resultado subraya la importancia que tienen, dada la respuesta del sector, los programas gubernamentales que están en operación actualmente, orientados a lograr mayores rendimientos.

A pesar de que el efecto sobre la producción total era muy pequeño se consideró interesante hacer el mismo cálculo para el caso de mayores exportaciones (caso 5, en comparación con el 2). En términos sectoriales agregados, este es un desplazamiento menor en la demanda que el originado por el cambio de $7 \%$ a $8 \%$ en el crecimiento del PIB y también está concentrado en un conjunto diferente de cultivos. Las exportaciones adicionales en el caso 5 son principalmente exportaciones de frutas y legumbres y provienen de las principales zonas productoras de riego. Esta elasticidad de la oferta de equilibrio a corto plazo con énfasis en la exportación, tiene un valor muy pequeño: +0.342 . Como está definida en el corto plazo, las inversiones y el aumento de rendimientos no entran en el panorama; sin embargo, es significativamente más pequeña que la elasticidad para todo el sector de +1.383 , definida de la misma manera.

La explicación de esta diferencia en los valores parece ser la siguiente: dados la disponibilidad de recursos y los rendimientos por hectárea, las zonas de temporal en la república, parecen tener en conjunto (para todos los cultivos) un mayor potencial de respuesta respecto al precio, debido a la existencia de tierras marginales no cultivadas, que serán incorporadas al cultivo de manera gradual, conforme a que los incentivos del precio se eleven. En contraste, prácticamente toda la tierra cultivable de riego está ya cultivada ${ }^{22}$ debido a los niveles más elevados de redituabibilidad. La confirmación de esta explicación se encuentra en los resultados de cHAC.

En la solución para 1968, 29.3\% de la tierra de temporal disponible no estaba cultivada en los meses críticos de trabajo en el campo. En la solución para 1976 con $7 \%$ de crecimiento en el PIB, el grado de ociosidad de la tierra se redujo a $8.3 \%$ y en la solución para 1976 , con $8 \%$ de crecimiento, se redujo aún más, hasta el $0.2 \%$.

" Se puede considerar como una función de oferta individual, a la línea que une los puntos $c$, $a$ y $b$. En este caso la elasticidad arco entre los puntos $c$ y $b$ proporciona un valor de +2.631 .

Excepto para zonas afectadas por problemas de tenencia y otros problemas, los cuales no responden a incentivos en los precios. 
El agotamiento de la tierra ociosa con $8 \%$ de crecimiento global, también implica que la elasticidad oferta resultaría menor a tasas de crecimiento más elevadas.

Esta explicación coincide con las observaciones de los estudiosos de la agricultura mexicana, en que por lo menos en un decenio los términos de comercio y por lo tanto los incentivos para cultivar las tierras marginales se han deteriorado constantemente desde el punto de vista del sector. Por lo tanto, en el momento actual de la agricultura mexicana, los incentivos del precio deben constituir estímulos poderosos para la expansión de las tierras cultivadas por particulares. Este resultado enfatiza la importancia que tienen las recomendaciones del Programa en cuanto a utilizar como instrumentos de desarrollo agrícola los incentivos del precio. Asimismo, una deducción complementaria que tiene relevancia para los programas de acción es la siguiente: en la medida que las imperfecciones de los mercados y las barreras socioculturales, etc., impidan la comunicación de los incentivos del precio a la mayoría de los agricultores de temporal, la respuesta de la oferta del sector seguirá siendo débil.

\section{Sustitución entre capital y mano de obra}

Como un resultado macroeconómico final, se presentan las estimaciones de la elasticidad de sustitución entre factores. Los factores de interés en este caso son el capital y la mano de obra. En un sentido general hay tres tipos de capital en el sector: a) la disponibilidad física de tierra, los sistemas de regadíos, los edificios y otras formas de capital fijo; b) la maquinaria agrícola; y c) capital circulante. En relación al financiamiento, el primer tipo por lo general corresponde a inversiones a largo plazo de duración de 10 o más años. El segundo corresponde a financiamiento a plazo medio, de dos a cinco años y el tercero corresponde a préstamos a corto plazo, a no más de un año.

En agricultura, el capital a largo plazo por lo general es complementario y no sustituto de la mano de obra. Los aumentos en la cantidad de tierra cultivable, aumentan las posibilidades de empleo; los aumentos en la disponibilidad de agua de riego por hectárea permiten mayores rendimientos, el doble cultivo y la producción de productos agrícolas intensivos en mano de obra, tales como frutas y hortalizas. Los aumentos en la cantidad de edificios amplían la capacidad de almacenamiento $\mathrm{y}$ aumentan las perspectivas de venta y por tanto de producción.

Por otro lado, el capital a plazo medio como el incorporado en la maquinaria agrícola, es un sustituto directo de la mano de obra en el campo. Por lo tanto, para analizar las alternativas de política es importante distinguir entre los efectos de las dos clases de capital.

El capital a corto plazo puede ser complementario o sustituto respecto al uso del capital, dependiendo del trabajo en el campo al que se destine. 
En los estudios econométricos tradicionales, se agregan los dos primeros tipos de capital y algunas veces las tres clases. Por lo tanto, los efectos tanto positivos como negativos, han sido agregados, el signo que domina y su monto dependen de: $a$ ) la fuerza de los dos efectos opuestos; y $b$ ) los pesos relativos de las diferentes clases de capital dentro del capital total del sector. Por ejemplo, Behrman, hizo estimaciones econométricas para Chile, de las elasticidades sectoriales de sustitución entre factores, con base en datos de series de tiempo que registran tanto maquinaria como otras formas de capital. ${ }^{23} \mathrm{El}$ valor de todas las elasticidades calculadas es menor que la unidad y la estimación para el sector agrícola es 0.31 .

Las estimaciones de CHAC se refieren solamente a la segunda clase de capital - la maquinaria - y por lo tanto, miden solamente el efecto sustitución sin ninguna mezcla de efectos con signo opuesto.

Por esta razón se podría esperar que las elasticidades de sustitución entre factores de CHAC sean de valor más alto y de hecho lo son: de 1.0 a más de 3.0, de acuerdo a diferentes definiciones como se presentó antes. A pesar de que estas estimaciones no toman en cuenta todas las formas de capital fijo en el sector, son útiles para propósitos de política porque miden el efecto puro de sustitución. También, dado que el financiamiento de la maquinaria es por lo general a un plazo diferente al de la inversión en tierra, en obras de regadío y en edificios, la separación conceptual para los cálculos de la elasticidad coinciden con la separación de los instrumentos de política.

Para estos cálculos, la mano de obra ha sido definida de manera que incluye agricultores y sus familiares, además de mano de obra asalariada para trabajos en el campo. Los tractoristas no se han tomado en cuenta ya que constituyen una parte insignificante de la fuerza de trabajo.

Los experimentos se orientan a realizar incrementos proporcionales en los salarios para todas las clases de mano de obra. ${ }^{24}$ Sin embargo, el salario sólo es una parte del costo de la mano de obra ya que los agricultores perciben el ingreso que proviene de su propia mano de obra y de la posesión de otros recursos como tierra y agua.. ${ }^{25}$ Por lo tanto, el costo el factor mano de obra fue medido como el ingreso neto total que proviene de todos los tipos de mano de obra dividido por el total de años hombres trabajados. Los incrementos en el salario nominal se utilizan como un medio de provocar movimientos a lo largo de la isoquanta. El costo de la mano de obra tal y como es medido, siempre que se eleva en una proporción menor que los incrementos en el salario nominal, ya que los agricultores pierden parte de su ingreso mientras que el costo de producción, que incluye el salario, se eleva. También, los salarios

Véase a Behrman (3).

${ }^{24}$ Hay que destacar que los salarios difieren entre las cuatro grandes regiones de CHAC así como entre agricultores y jornaleros.

${ }_{25}^{25}$ Ya que no hay limitaciones físicas acerca de la existencia de maquinaria agrícola, este factor no da lugar a rentas económicas. 
mayores tienden a desplazar el empleo de los jornaleros hacia los agricultores, cuyo salario mínimo es menor que el salario del mercado.

Por lo tanto, las dos características importantes de las elasticidades de CHAC respecto a la sustitución entre factores son: a) se refieren solamente a capital a mediano plazo; y $b$ ) la falta de homogeneidad en la mano de obra. Otra característica importante es que estas elasticidades están basadas en una función de producción sectorial de factores múltiples. La tierra y el agua son dos factores cuya disponibilidad está especificada en ambos casos en forma mensual, en cada localidad. La cantidad de tierra y de agua usada es endógena en el modelo, pero su disponibilidad es fija. En términos formales, esta función de producción de factores múltiples corresponde estrechamente al modelo de análisis de procesos descrito y analizado por Georgescu-Roegen. ${ }^{26}$ En su terminología la tierra y el agua son "fund factors" (factores de acumulación) y su omisión en los estudios empíricos tradicionales es un defecto desde su punto de vista.

Una cuarta característica de interés, es que la función de producción sectorial de CHAC es de productos múltiples ( 33 en total). Esto impone algunos problemas respecto a cuáles conceptos mantener constantes para definir la isocuanta. En las soluciones que se presentan se analizan tres funciones: a) el ingreso de los productores (utilidades) se mantiene constante; $b$ ) nada se mantiene constante; y $c$ ) el valor total de la producción se mantiene constante. Dado que el ingreso de la mano de obra se compone en parte por las utilidades, se podría esperar que la primera definición proporcionará una sustitución menor entre factores, lo que es exactamente como sucede. Esta definición es la de una curva de isoganancias. La segunda definición no proporciona una isoquanta sino más bien es el lugar geométrico de puntos de equilibrio general asociados a cambios en los precios de los factores. Si bien esto no es una isocuanta, tiene un interés mayor para los encargados de tomar decisiones de política agrícola, porque constituye una estimación completa del conjunto de reacciones a cambios hipotéticos en los precios. Constituye un tipo de superación de respuesta. ${ }^{27}$ Entre otros casos, es interesante ver qué tanto se aproxima la isoquanta a la superficie de respuesta. La tercera definición es algo muy cerca de la isocuanta misma porque, como se explica más adelante, asegura que la producción, medida por un índice de quantum, se mantenga más o menos constante.

Como un punto final en las definiciones y antes de presentar los resultados numéricos, hay que mencionar que la función de producción de CHAC también está especificada en relación con la utilización de varios

${ }^{20}$ Véase Georgescu-Roegen (9) y (10).

27 Se debe señalar que las isocuantas fueron definidas inicialmente no debido a su importancia en relación a los problemas de política sino porque se pueden estimar rápidamente como un resultado parcial de los modelos analíticos. La utilización de modelos numéricos de simulación ha hecho posible superar el concepto de la isocuanta e ir directamente al problema de estimar superficies de respuesta. 
insumos en el proceso de producción. Estos insumos tienen un precio, pero no están restringidos de ninguna manera en las soluciones que se presentan más adelante.

La elasticidad sectorial, respecto a la sustitución de factores, medida a través del arco más largo desde el punto cero hasta el fin del segmento 5 es 0.956 , cuando las ganancias de los productores se mantienen constantes en 1.395 para el caso de puntos de equilibrio no restringidos (El caso de la isocuanta propiamente dicha se comenta más adelante). El cuadro 2 y la gráfica 3 muestran los cálculos y las "isocuantas". Es interesante destacar, en primer lugar, que el lugar geométrico de los múltiples puntos de equilibrio de mercado (caso II en el cuadro 2) muestra mayor sustituibilidad de factores que la curva de isoganancia. Dicho de otra manera, la utilización de la curva de isoganancia subestima el grado de la respuesta sectorial total que es el punto importante para la formulación de políticas agrícolas. En segundo lugar, ambas curvas tienen elasticidades que varían bastante a lo largo de los diferentes segmentos y en algunos casos no son convexas. Este comportamiento fue predecido por el profesor Georgescu-Roegen en sus estudios respecto a la función de producción en el análisis de procesos. La falta de convexidad surge del hecho de que chac es. un modelo de productos y factores múltiples y las "isocuantas" son proyecciones de un hiperplano multidimensional sobre un espacio euclidiano de dos planos. Geosgescu-Roegen ha mostrado que este resultado no debe ser considerado como sorprendente al provenir de un modelo formulado de acuerdo al análisis de procesos. La pregunta metodológica que surge de estos resultados es la siguiente: si el modelo de producción planteado de acuerdo al análisis de procesos, es una representación razonable de la realidad, ¿qué tan válidos son los parámetros de sustitución estimados mediante: a) el ajuste de datos a un modelo de producción, que lleva el supuesto de elasticidades de sustitución constantes y $b$ ) una función de producción de dos factores y un producto?

Un aspecto interesante de los resultados de la sustitución entre capital y mano de obra, es que la curva de isoganancias proporciona niveles de ingreso neto a los trabajadores que siempre son más altos a medida que el salario se eleva y por tanto los niveles de empleo son menores de manera uniforme. La razón de éste hecho se aprecia claramente en el cuadro 2. Destaca en primer lugar, que al mantener las ganancias constantes no se permite que los ingresos de los productores disminuyan mientras qu los salarios se elevan. La única forma para mantener constantes las utilidades ante costos crecientes de producción, es mediante una elevación de los precios de los productos. En segundo lugar, destaca que los niveles físicos de producción son menores con la curva de isoganancias que en el caso de puntos de equilibrio. Dado que la producción agrícola por lo general tiene una elasticidad precio de la demanda menor que la unidad (en valor absoluto), niveles menores de producción, elevan de manera sustancial las ganancias de los productores para 
Cuadro 2

MODElo CHAC: ELASTICidADES DE SUSTITUCIÓN ENTRE FACTORES

\begin{tabular}{|c|c|c|c|c|c|c|}
\hline & \multicolumn{6}{|c|}{ Sogrento de Ia 1soouanta } \\
\hline & 0 & 1 & 2 & 3 & 4 & 5 \\
\hline \multicolumn{7}{|c|}{ Cago Is oon genanos as oonstantos do eroduotores } \\
\hline$\underline{x}^{2}$ & 2311.50 & 2342.60 & 2374.30 & 2403.60 & 2439.30 & 2478.90 \\
\hline $\mathrm{E}^{\mathrm{b} /}$ & 927.79 & 925.71 & 927.71 & 927.71 & $\$ 27.71$ & 927.71 \\
\hline tof & 512.40 & 554.09 & 558.67 & 595.31 & 621.72 & 653.38 \\
\hline 量 & 1440.11 & 1481.72 & +486.38 & 1523.02 & 1549.43 & 1581.09 \\
\hline$\overline{\mathrm{z}}$ & 2015.59 & 1988.64 & 1884.04 & 1856.56 & +818.29 & 1799.33 \\
\hline $\mathbf{I} / \mathbf{B}$ & 0.7145 & 0.7451 & 0.7889 & 0.8203 & 0.8521 & 0.8787 \\
\hline$\underline{\underline{x}} \pm$ & 856.5500 & 858.0400 & 911.6700 & 913.5800 & 942.1600 & 941.6400 \\
\hline 尔 & 0.1200 & 0.1200 & 0.1200 & 0.1200 & 0.1200 & 0.1200 \\
\hline$\underline{\underline{\mathbf{z}}} / \mathbf{\underline { \mathbf { E } }}$ & 0.4294 & 0.4315 & 0.4839 & 0.4921 & 0.5182 & 0.5233 \\
\hline$(\underline{I} / \mathbf{B})$ 息 & 5.9542 & 6.2092 & 6.5742 & 6.8358 & 7.1008 & 7.3225 \\
\hline Blastioided (a) & & +0.1160 & +2.0050 & +0.4300 & +1.3590 & +0.3190 \\
\hline Blawtiojdad (b) & & +0.1160 & +1.2060 & +0.9870 & +1.0670 & +0.9560 \\
\hline \multicolumn{7}{|c|}{ 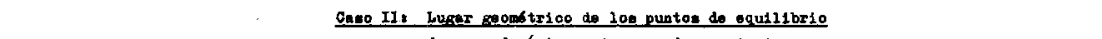 } \\
\hline & & do mexot & edn manterax & oonatante & & \\
\hline$\underline{\underline{x}}$ & 2311.50 & 2276.9 & 2356.40 & 2391.20 & 2390.70 & 2403.70 \\
\hline 严 & 927.71 & 847.80 & 902.90 & 901.21 & 856.27 & 840.25 \\
\hline 些 & 512.40 & 560.96 & 560.24 & 596.75 & 623.18 & 653.58 \\
\hline 恶 & 1440.11 & 1408.76 & 1463.14 & 1497.96 & 1479.45 & 1493.83 \\
\hline$\underline{E}^{\circ /}$ & 2015.59 & 2009.31 & 1890.18 & 1863.54 & 1829.00 & 1802.30 \\
\hline $\mathrm{I} / \mathrm{S}$ & 0.7145 & 0.7011 & 0.7741 & 0.8038 & 0.8089 & 0.8288 \\
\hline$\underline{\underline{x}}^{\underline{5}}$ & 865.5500 & 861.7200 & 915.6000 & 929.5500 & 963.0100 & 952.2900 \\
\hline $\bar{g}$ & 0.1200 & 0.1200 & 0.1200 & 0.1200 & 0.1200 & 0.1200 \\
\hline$\underline{\mathbf{S}} \mathbf{E}$ & 0.4294 & 0.4289 & 0.4844 & 0.4988 & 0.5265 & 0.5284 \\
\hline$(\mathbf{y} / \mathbb{E}) / \mathbf{R}$ & 5.9542 & 5.8425 & 6.4508 & 6.5983 & 6.7408 & 6.9067 \\
\hline Blantioided (a) & & +0.0620 & +1.2280 & +0.7790 & $+8+5430$ & +0.1490 \\
\hline B2antiolded (b) & & +0.0620 & +1.5040 & +1.2720 & +1.6390 & +1.3950 \\
\hline
\end{tabular}

a Valor de la producción, definido como un índice de cantidad de Laspeyres. Las unidades son 10 millones de pesos, a precios de 1968.

- Ganancias de los producto:es estimadas como la suma de los ingresos económicos que provienen de la tierra, el agua y la mano de obra familiar. Expresadas en las mismas unidades que las indicadas para la producción.

- Ingreso por salarios, que comprende pagos de salarios a los jornale:os, más pagos del salario a la mano de obra familiar. Las unidades son las mismas que las arriba indicadas.

d El ingreso total de la mano de obra, estimado como la suma de $P$ y $W$.

- Empleo (medido en miles de años-hombre): incluye el empleo tanto de mano de obra de los jornaleros como de la mano de obra familiar.

- Uso de maquinaria, medido como iun flujo anual de servicios de maquinaria, valuada en unidades de 10 millones de pesos.

* Tipo de interés.

${ }^{\text {h }}$ La elasticidad (a) es la elasticidad arco medida entre los puntos contiguos de los segmentos lineales de la "isocuanta". Por ejemplo del principio del segmento 1 al principio del segmento 2 es +2.005 en el caso I. La elasticidad (b) está medida del segmento 0 al principio del segmento en cuestión. Así, el arco más largo es el del 0 al 5 con elasticidad de +0.956 (caso I), y +1.395 (caso II). El "segmento 0" es solo un punto que corresponde a la solución base. La elasticidad está siempre medida como el porciento de cambio en las proporciones de factores dividido por el porciento de cambio en la razón de precios de los factores. Véase Ferguson (8) para la metodología de cálculo de elasticidades en una isocuanta de segmentos lineales. 
compensar los mayores costos de producción. Esta cadena de reacciones se refleja en el hecho do que mientras el índice de producción es siempre menor para la curva de isoganancias en comparación con la de puntos de equilibrio, el valor de la producción a precios endógenos, es siempre mayor para la curva de isoganancias.

Por lo tanto, imponer en el modelo ganancias constantes de los productores, requiere de un conjunto de cambios que se compensen tanto en los niveles de producción como en los precios de los productos. Estos cambios son del todo diferentes a la respuesta libre del mercado; en el caso de puntos de equilibrio el valor de la producción no se eleva de manera tan rápida ni uniforme.

Debido a estos efectos en la producción, la curva de isoganancias no sólo subestima la elasticidad de sustitución, también subestima el nivel absoluto de utilización de capital y mano de obra en todos los segmentos, en comparación con la curva de respuesta en equilibrio en todos los puntos.

En resumen, ambas curvas captan tanto el efecto de producción como el de sustitución. Si bien preferimos utilizar la curva de respuesta en lugar de la curva de la isoganancia hay que reconocer que ninguno de estos conceptos permite medir un efecto de sustitución puro. Por lo tanto, para aislar este efecto de sustitución, se formuló con CHAC un tercer conjunto de segmentos en los que se mantiene constante el valor de la producción (a precios endógenos). Estos resultados se presentan (como caso III) en el cuadro 3.

\section{Cuadro 3}

Modelo Chac: Elasticidades de sustitución ENTRe factores PaRa EL CASO $\mathrm{III}^{\mathrm{a}}$ (valor de la producción constante)

\begin{tabular}{|c|c|c|c|c|c|c|}
\hline \multirow{2}{*}{ Tariables } & \multicolumn{6}{|c|}{ Segmento de la igoouanta } \\
\hline & 0 & 1 & 2 & 3 & 4 & 5 \\
\hline 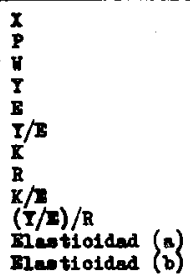 & $\begin{array}{r}2311.5 \\
927.71 \\
512.40 \\
1440.11 \\
2015.59 \\
0.7145 \\
865.55 \\
0.1200 \\
0.42943 \\
5.9542\end{array}$ & $\begin{array}{r}2.311 .5 \\
880.55 \\
561.36 \\
1441.91 \\
2010.58 \\
0.7172 \\
863.72 \\
0.1200 \\
0.42936 \\
5.9767 \\
-0.043 \\
-0.043\end{array}$ & $\begin{array}{r}2311.5 \\
853.36 \\
560.92 \\
1414.28 \\
1894.16 \\
0.7467 \\
919.96 \\
0.1200 \\
0.4857 \\
6.2225 \\
+3.053 \\
+2.792\end{array}$ & $\begin{array}{r}2311.5 \\
807.48 \\
600.12 \\
1407.60 \\
1873.75 \\
0.7512 \\
942.59 \\
0.1200 \\
0.5031 \\
6.2600 \\
+5.857 \\
+3.157\end{array}$ & $\begin{array}{r}2311.5 \\
767.59 \\
622.51 \\
1390.10 \\
1832.14 \\
0.7587 \\
975.57 \\
0.1200 \\
0.5325 \\
6.3225 \\
+5.710 \\
+3.573\end{array}$ & $\begin{array}{r}2311.5 \\
729.15 \\
653.70 \\
1382.85 \\
1810.25 \\
0.7639 \\
972.61 \\
0.1200 \\
0.5373 \\
6.3658 \\
+1.314 \\
+3.341\end{array}$ \\
\hline
\end{tabular}

a Las unidades y los procedimientos de cálculo son los mismos que en el cuadro 2 .

Al revisar los casos I y II, es posible decir que el caso I (que considera constantes las ganancias de los productores) forza los niveles físicos de producción a disminuir más que en el caso de libre respuesta. Sin em- 
Gráfica 3

ISOCUANTAS SECTORIALES DE SUSTITUCIÓN ENTRE CAPITAL Y MANO DE OBRA

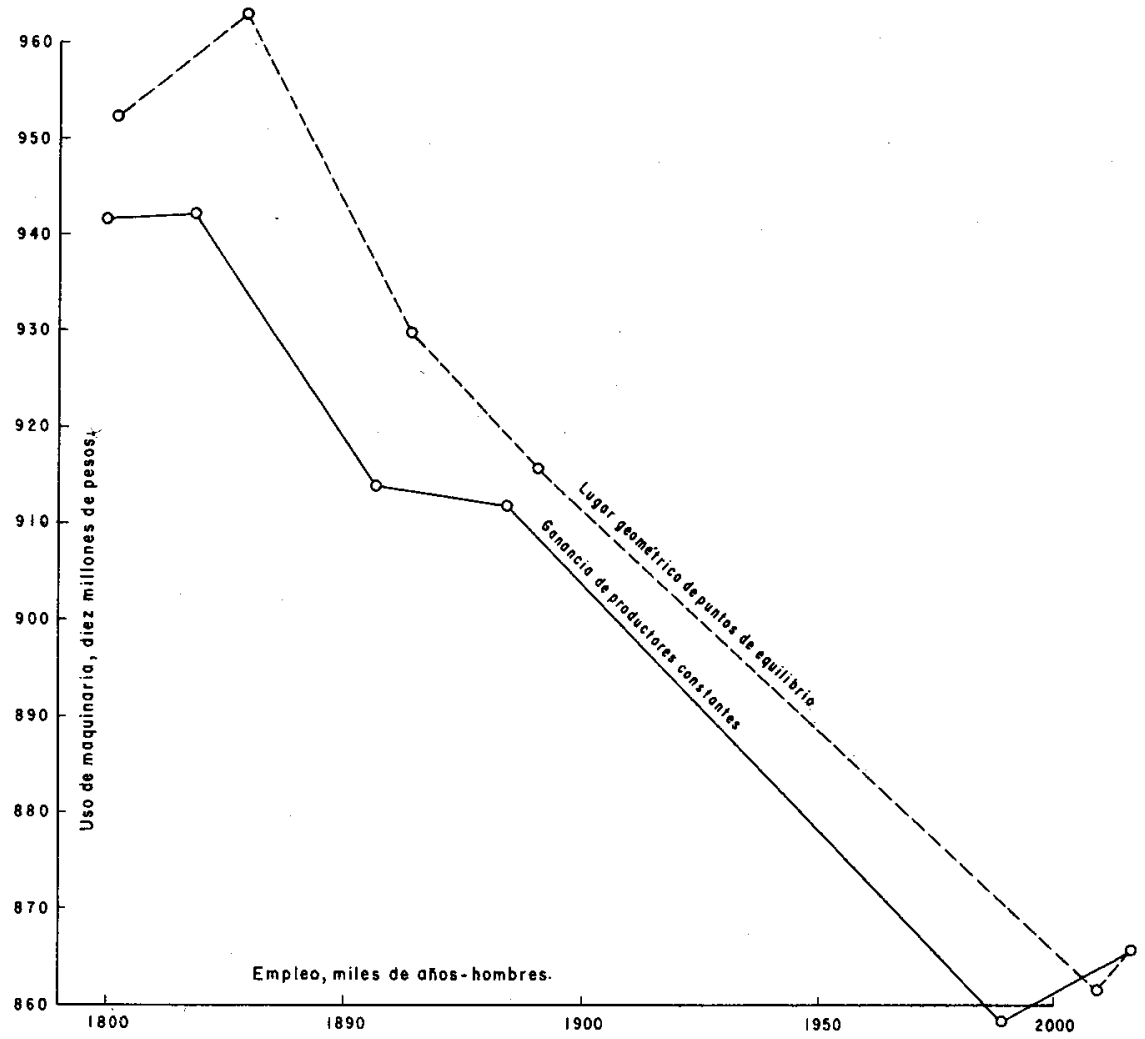


bargo, en este caso también disminuyen ${ }^{28}$ los niveles dado que los incrementos de salarios representan aumentos en los costos de producción. El caso III por definición no permite que el nivel físico de la producción disminuya. Este concepto se maneja en CHAC manteniendo constante el valor de la producción. Dado que la elasticidad-precio media de la demanda sectorial no es igual a la unidad, esto significa que el índice de quantum de la producción sectorial también debe ser casi constante permite compensar cambios entre productos individuales. Por lo tanto, el caso IIl proporciona niveles físicos de producción más altos y un nivel más elevado de utilización, para ambos factores, que en el caso l o el II.

La elasticidad de sustitución pura calculada de esta manera se presenta en el cuadro 3. Como era de esperar, es con mucho más alta que en los casos I y II, ya que, medida a través del arco más largo, se calcula en + 3.341. Si bien esta medida es más pura conceptualmente, para estimarla se ha necesitado imponer una restricción en el modelo, relacionada con la respuesta del mercado. Esta restricción ha forzado a que el valor de la producción total difiera de manera significativa de los niveles registrados en el caso de la respuesta del mercado sin ninguna restricción. ${ }^{30}$ Por esta razón se considera que el caso II es el más útil para propósitos de política económica. Dada la discrepancia existente entre las estimaciones de la elasticidad con los casos II y III, la pregunta pragmática que surge cuando se formulan recomendaciones de política económica es la de que en algunos casos es adecuado utilizar elasticidades de sustitución que se derivan de isocuantas, en lugar de superficies de respuesta.

Como un punto final de interés, el cuadro 4 muestra la "elasticidad salario del empleo" para todos los segmentos y en todos los casos. Este concepto está medido como el porciento de respuesta en los niveles de empleo dividido por el porciento de cambio en el ingreso total de la mano de obra (salarios más ganancias de los productores). Como indica el cuadro, hay una variación sustancial a lo largo de cada curva y entre definiciones de conceptos de la isocuanta. De nuevo el caso III, en donde la producción se mantiene constante, muestra el mayor grado de respuesta. El valor límite de esta elasticidad es - 1.606 en el caso III. mientras que es -0.754 en el caso II y -0.550 en el caso I.

Si la superficie de respuesta en el caso II es en verdad el concepto de interés para los propósitos de formulación de programas, entonces el uso de la producción constante (isocuanta) sería engañador ya que sobrestima por más del doble el porciento de respuesta del empleo a cambios en los salarios.

\footnotetext{
* A lo largo de algunos segmentos de esta curva, la disminución en la producción física, implica la disminución en el valor de la producción, porque algunos cultivos se enfrentan a una demanda relativamente elástica al precio. En estos segmentos, esos productos son los que presentan las mayores variaciones.

$\rightarrow$ No es exactamente constante debido a problemas en el cálculo de los números índices.

${ }^{30}$ La diferencia en el valor de la producción sectorial entre los casos II y III es alrededor de $4 \%$ y nunca excede el $3 \%$ entre los casos I y II.
} 


\section{Cuadro 4}

Elasticidad ${ }^{a}$ Salario del empleo en las isocuantas y en el lugar GEOMÉTRICO DE PUNTOS DE EQUILIBRIO

\begin{tabular}{|c|c|c|c|c|c|}
\hline \multirow{2}{*}{$0000, b /$} & \multicolumn{5}{|c|}{ Sogenanto de la zeoouan ta } \\
\hline & 1 & 2 & 3 & 4 & 5 \\
\hline$I(8)$ & $\begin{array}{l}-0.321 \\
-0.321\end{array}$ & $\begin{array}{l}-0.946 \\
-0.682\end{array}$ & $\begin{array}{l}-0.376 \\
-0.596\end{array}$ & $\begin{array}{l}-0.548 \\
-0.586\end{array}$ & $\begin{array}{l}-0.342 \\
-0.550\end{array}$ \\
\hline II $\left\{\begin{array}{l}a \\
b\end{array}\right)$ & $\begin{array}{l}+0.165 \\
+0.165\end{array}$ & $\begin{array}{l}-0.617 \\
-0.802\end{array}$ & $\begin{array}{l}-0.377 \\
-0.666\end{array}$ & $\begin{array}{l}-2.958 \\
-0.783\end{array}$ & $\begin{array}{l}-0.605 \\
-0.754\end{array}$ \\
\hline III $\left(\begin{array}{l}0 \\
b\end{array}\right)$ & $\begin{array}{l}-0.660 \\
-0.660\end{array}$ & $\begin{array}{l}-1.480 \\
-1.409\end{array}$ & $\begin{array}{l}-0.1803 \\
-1.456\end{array}$ & $\begin{array}{l}-2.260 \\
-1.589\end{array}$ & $\begin{array}{l}-1.760 \\
-1.606\end{array}$ \\
\hline
\end{tabular}

"La elasticidad está definida como el porciento de cambio en el empleo, dividida por el porciento de cambio en el ingreso total de la mano de obra (variables $E$ e $Y$ en los primeros cuadros).

${ }^{b}$ Los tres casos se definen con los cuadros 2 y 3. Como ya se mencionó, la estimación (a) se refiere sólo a la abertura del arco en un segmento y la (b) al alcance del arco desde el segmento cero hasta el final del segmento relevante. Las elasticidades están siempre calculadas en el punto medio del arco.

En un segmento del caso II el signo es positivo, es decir, tanto el empleo como el ingreso total por año-hombre disminuyen. Esto es atribuible en parte a la compleja estructura de la determinación del ingreso de la mano de obra en el modelo. Al considerar sólo el salario ( $\mathrm{y}$ no las ganancias de los productores) en el cuadro 2, la elasticidad salario del empleo para ese segmento, tiene el signo usual y su valor es -0.033 .

\section{REsultados PaRa CUltivos INDividuales}

\section{Ventajas comparativas en la exportación}

Si se utilizan los resultados de la solución dual de CHAC, se pueden "evaluar" los cultivos de exportación en términos de las ganancias que representan para México unidades adicionales de exportación o importación. La estimación del costo en pesos de un dólar adicional de ganancias de divisas, puede ser calculada de acuerdo con la metodología de Bruno ${ }^{31}$ mediante los valores de la solución dual. El cuadro 5 muestra este costo, que constituye el costo de intercambio para los productos de exportación en varias soluciones. ${ }^{3: 2}$ Al tipo de cambio prevaleciente, los cultivos con un costo de intercambio menor de 12.5 pesos, son redituables para exportaciones en el margen (o para incrementar las exportaciones marginales si es que ya se están exportando). En el mismo sentido y también

"31 Véase, Bruno (4).

${ }^{32}$ Para mayores detalles respecto a cómo se calcula el costo de intercambio, véase Duloy y Norton (6). 
en términos estáticos, el bienestar del país sería mayor si se importara, en vez de producirlos internamente, cantidades marginales de los productos agrícolas cuyo costo de intercambio es mayor de 12.5 pesos, con la precaución de que esos recursos productivos fueran asignados a aquellos con un costo menor de exportación. Este requisito es importante sobre todo en el caso del maíz, dado que no es posible sustituir su cultivo por otros, en el corto plazo, en varias regiones de temporal. Sin embargo, el alto costo de exportación de maíz tiene implicaciones para la política de largo plazo. Esto significa que se debe realizar un esfuerzo mayor para elevar los rendimientos de maíz ${ }^{33}$ o para facilitar la adopción de cultivos de valor más alto.

\section{Cuadro 5}

CAMbIOS EN LAS VENTAJAS COMPARATIVAS DE LAS EXPORTACIONES EN EL TRANSCURSO DEL TIEMPO

\begin{tabular}{|c|c|c|c|c|c|c|}
\hline \multirow{2}{*}{ Oult 1vo } & \multicolumn{6}{|c|}{ Costo do interosebilo } \\
\hline & 1968 & rango & $\begin{array}{r}1976 \\
(7 \%)^{2}\end{array}$ & rango & $\begin{array}{c}1976 \\
(8 \%)\end{array}$ & $\operatorname{ran} 8^{\circ}$ \\
\hline 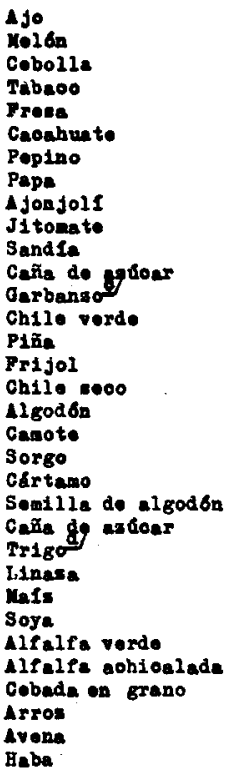 & $\begin{array}{l}3.13 \\
3.69 \\
3.89 \\
3.99 \\
4.65 \\
5.45 \\
5.84 \\
5.86 \\
5.94 \\
6.22 \\
6.49 \\
6.61 \\
6.73 \\
9.48 \\
10.53 \\
11.31 \\
12.39 \\
12.39 \\
14.06 \\
16.25 \\
16.58 \\
19.02 \\
19.58 \\
20.33 \\
20.54 \\
21.00 \\
20.23 \\
22.50 \\
24.43 \\
25.48 \\
28.25 \\
30.39 \\
33.46\end{array}$ & $\begin{array}{r}1 \\
2 \\
3 \\
4 \\
5 \\
6 \\
7 \\
8 \\
9 \\
10 \\
11 \\
12 \\
13 \\
14 \\
15 \\
16 \\
17 \\
17 \\
19 \\
20 \\
21 \\
22 \\
23 \\
24 \\
25 \\
26 \\
27 \\
28 \\
29 \\
30 \\
31 \\
32 \\
33\end{array}$ & $\begin{array}{l}3.28 \\
3.94 \\
4.28 \\
4.10 \\
3.47 \\
6.50 \\
6.31 \\
6.73 \\
5.74 \\
6.89 \\
7.51 \\
8.27 \\
7.12 \\
10.83 \\
9.88 \\
11.80 \\
13.70 \\
12.39 \\
14.63 \\
16.48 \\
18.16 \\
40.71 \\
22.92 \\
21.92 \\
24.39 \\
24.39 \\
26.51 \\
29.25 \\
22.94 \\
32.20 \\
34.38 \\
34.72 \\
44.98\end{array}$ & $\begin{array}{r}1 \\
3 \\
5 \\
4 \\
2 \\
8 \\
7 \\
9 \\
6 \\
10 \\
12 \\
13 \\
11 \\
15 \\
14 \\
16 \\
18 \\
17 \\
19 \\
80 \\
21 \\
32 \\
23 \\
22 \\
25 \\
25 \\
27 \\
28 \\
24 \\
29 \\
30 \\
31 \\
33\end{array}$ & $\begin{array}{r}3.37 \\
4.04 \\
4.40 \\
3.99 \\
3.51 \\
6.50 \\
6.41 \\
6.78 \\
5.70 \\
8.69 \\
7.66 \\
8.45 \\
7.32 \\
10.88 \\
9.59 \\
12.13 \\
13.96 \\
12.39 \\
14.78 \\
17.06 \\
19.03 \\
43.56 \\
23.75 \\
23.20 \\
25.03 \\
25.21 \\
27.83 \\
30.25 \\
24.13 \\
33.36 \\
35.38 \\
36.20 \\
45.73\end{array}$ & $\begin{array}{r}1 \\
4 \\
5 \\
3 \\
2 \\
8 \\
7 \\
9 \\
6 \\
13 \\
11 \\
12 \\
10 \\
15 \\
14 \\
16 \\
18 \\
17 \\
19 \\
20 \\
21 \\
32 \\
23 \\
22 \\
25 \\
26 \\
27 \\
28 \\
24 \\
29 \\
30 \\
31 \\
33\end{array}$ \\
\hline
\end{tabular}

a Con $7 \%$ de crecimiento del $P I B$

b Con $8 \%$ de crecimiento del $P I B$

c Mercado norteamericano

d Mercado mundial.

* En forma más precisa, aumentar la productividad económica de los recursos utilizados en la producción de maíz. 
Cuadro 5-A

COSTO DE INTERCAMBIo PONDERADo CON EXPORTACIONES (pesos y toneladas)

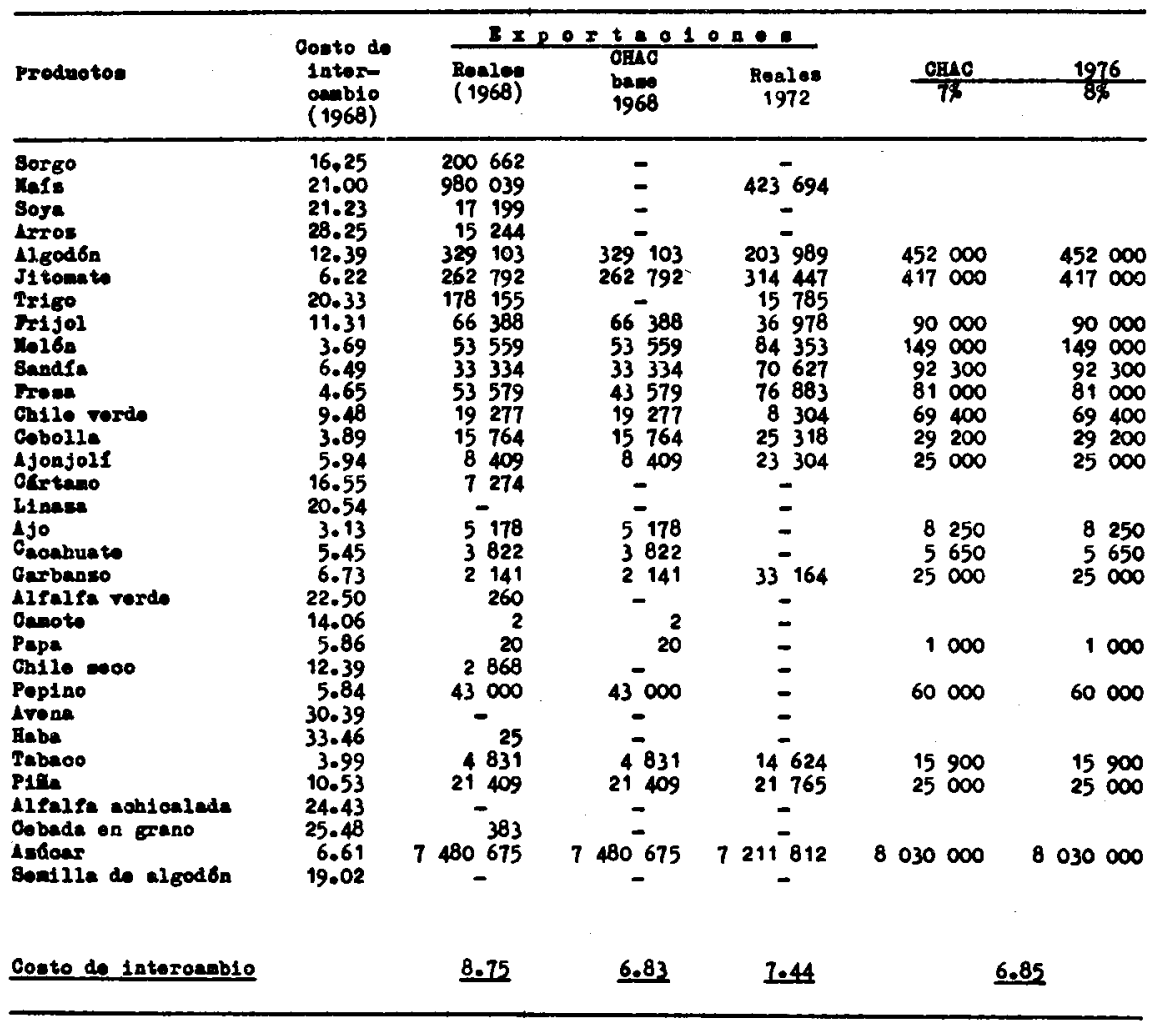

El cálculo de los costos de intercambio a 1976, no tomó en cuenta el cambio en los precios del mercado mundial a partir de 1968, para hacer énfasis en ciertos puntos que se presentan a continuación. Para una evaluación completa de las estrategias de política comercial, sería útil repetir los cálculos y considerar los precios recientes en el mercado mundial. Sin embargo, también sería necesario relocalizar las curvas de demanda interna para tomar en cuenta los efectos de la inflación.

De este cuadro destacan diversos aspectos. En primer lugár la jerarquización de los cultivos no presenta variaciones fuertes en el transcurso del tiempo, en particular en los productos que tienen un costo de intercambio inferior a $\$ 12.5$. Dado que otros productos no se exportaron, en las soluciones del modelo, su costo de intercambio es menos representativo. En segundo lugar destaca que el costo medio ponderado de intercambio con las exportaciones endógenas del modelo como ponderacio- 
nes, se eleva un poco en el transcurso del tiempo. Esto significa que con una tasa de crecimiento de 7 o de $8 \%$, el sector agrícola está impelido a satisfacer las necesidades del mercado interno y los mercados de exportación se vuelven menos atractivos, en el margen, para los productores. Este resultado es congruente con la experiencia mexicana reciente, que muestra la participación relativa de las exportaciones que ha declinado respecto al total de la producción agrícola. Por supuesto, al considerar los programas que aumentan la disponibilidad de recursos agrícolas o los rendimientos unitarios, este resultado podría no ser válido.

El tercer punto que destaca del cuadro 5 es que el costo de intercambio, la media ponderada, respecto a las exportaciones realizadas en 1968 es mucho más alto que el calculado con las exportaciones del modelo. Sin embargo, las ganancias totales de divisas en CHAC no fueron muy diferentes de las del mundo real. Esto significa que todavía hay muchas oportunidades para mejorar los patrones de exportaciones agrícolas, aun considerando las restricciones existentes en la capacidad de absorción del mercado internacional (véase el cuadro 5-A).

El cuarto punto que destaca es que estas mejoras en la estructura de las exportaciones agrícolas ya se están realizando. Las exportaciones reales para 1972 proporcionan un costo de intercambio de 7.44 pesos en comparación con 8.75 pesos que es el costo de intercambio calculado con las exportaciones registradas en la realidad en 1968.

Ya sea que este hecho resulte de una política específica del gobierno o simplemente de las fuerzas del mercado, las recomendaciones respecto a dar énfasis diferente a las exportaciones agrícolas que surgieron de los primeros estudios realizados con CHAC, ya se están realizando.

Cuadro 6

VALOR DE LAS EXPORTACIONES DE LOS PRINCIPALES CULTIVOS (miles de pesos corrientes, precios al nivel de predio)

\begin{tabular}{|c|c|c|c|c|c|c|}
\hline \multirow{2}{*}{ Clase de cultivo } & \multicolumn{2}{|c|}{1968} & \multicolumn{2}{|c|}{1971} & \multicolumn{2}{|c|}{$1972^{a /}$} \\
\hline & Valor & क & Valor & \% & Valor & क \\
\hline \multirow{5}{*}{ 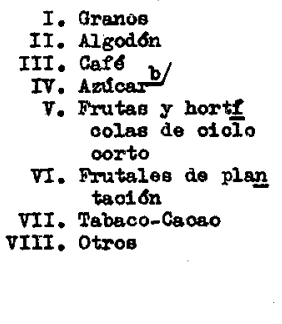 } & $\begin{array}{r}1014 \quad 446 \\
2065710 \\
726 \quad 651 \\
561021\end{array}$ & $\begin{array}{l}0.19 \\
0.39 \\
0.14 \\
0.11\end{array}$ & $\begin{array}{r}314840 \\
1254002 \\
767761 \\
546185\end{array}$ & $\begin{array}{l}0.08 \\
0.31 \\
0.19 \\
0.14\end{array}$ & $\begin{array}{r}442700 \\
1639369 \\
1214809 \\
579512\end{array}$ & $\begin{array}{l}0.08 \\
0.30 \\
0.22 \\
0.11\end{array}$ \\
\hline & 541186 & 0.10 & 893012 & 0.22 & 1106962 & 0.20 \\
\hline & $\begin{array}{rr}66 & 037 \\
75 & 227 \\
213 & 282\end{array}$ & $\begin{array}{l}0.01 \\
0.01 \\
0.04\end{array}$ & $\begin{array}{ll}60 & 793 \\
95 & 088 \\
85 & 093\end{array}$ & $\begin{array}{l}0.02 \\
0.02 \\
0.02\end{array}$ & $\begin{array}{r}39080 \\
180559 \\
275584\end{array}$ & $\begin{array}{l}0.01 \\
0.03 \\
0.05\end{array}$ \\
\hline & 5. 263560 & & 4016774 & & 5478575 & \\
\hline & & de & imionto anu & & $1.0 \%$ & \\
\hline
\end{tabular}

Fuente: Con base en datos de exportaciones por cultivos de la Dirección de Economía Agrícola, Secrearía de Agricultura y Ganadería.

Estimado.

b Valuado en términos de caña de ezúcar al nivel de la finca. 
Por lo tanto, y en respuesta a la presión creciente en el abastecimiento de productos agrícolas (como se señaló anteriormente en el punto II), la estructura de las exportaciones del mundo real se está adaptando estrechamente a los patrones de ventaja comparativa. La discrepancia inicial entre los costos de intercambio que surgen de CHAC y los del mundo real (6.83 en comparación con 8.75 pesos en 1968) han disminuído (6.85 en 1976 en cHAC en comparación con 7.44 en 1972) en la realidad. El cuadro 6 muestra como ha cambiado la estructura de las exportaciones en años recientes.

\section{CHAC como instrumento de predicción.}

CHAC no fue diseñado como instrumento de predicción, sino más bien para entender la flexibilidad del sector; esto es el grado en que puede esperarse que responda el sector agrícola a cambios en diversas políticas. Con este propósito incluye los principales productos e insumos del proceso de producción del sector y también los mercados tanto interno como externo. Ayuda a "evaluar", en términos cuantitativos, algunos conceptos, tales como la sustitución entre capital y mano de obra, las funciones de oferta sectorial, y las ventajas comparativas que tiene México en los mercados internacionales.

Sin embargo, es interesante observar cómo se comporta como instrumento de predicción. Obtener proyecciones razonables para la producción agrícola y para el consumo interno, es de gran utilidad en la formulación de políticas anuales en el proceso de planeación. CHAC proporciona proyecciones de producción razonables, y proyecciones de los requerimientos asociados de todos los insumos. Por lo tanto, se presentan algunas "evaluaciones" preliminares de las proyecciones del modelo, no como proyecciones definitivas, sino como resultados que ayudan a decidir si CHAC es básicamente útil como instrumento de predicción. Si el resultado es positivo, se pueden dedicar más esfuerzos a afinarlo con este propósito.

Para las proyecciones de producción se utilizó el "caso básico" a 1976 como se definió antes. Debe enfatizarse que la información incluida en el modelo respecto a las elasticidades de demanda no es muy reciente. Para las elasticidades ingreso, se utilizó la encuesta de ingresos y gastos del Banco de México, 1963, pero en varios casos se encontró que era necesario hacer algunas modificaciones arbitrarias en ellas, ya que algunas se distorsionaban a la luz de numerosas comparaciones internacionales. En CHAC, las elasticidades ingreso fueron especificadas por grupos de cultivos, por lo tanto, en la mayoría de los casos, las elasticidades individuales por cultivo no pueden ser conocidas sin saber como cambia la composición dentro del grupo a lo largo del tiempo. ${ }^{34}$ Las elasticidades ingreso para los grupos que entraron en el modelo son las siguientes:

\footnotetext{
${ }^{34}$ En pocos casos el grupo incluye sólo un producto.
} 
1. Granos (maíz, trigo)

2. Forrajes (sorgo, cebada, avena, alfalfa, garbanzo forrajero y maíz forrajero)

3. Féculas (frijol, arroz, papa, garbanzo)

4. Oleaginosas (semilla de algodón, ajonjolí, linaza, cacahuate, cártamo y soya '

5. Frutas (sandía, melón, fresa, piña)

6. Condimentos (cebolla, ajo)

7. Chiles (chile verde, chile seco)

8. Azúcar

0.400

9. Jitomate

10. Algodón

11. Camote

12. Haba

0.400

13. Tabaco

14. Cebada malta

15. Pepino

0.598

16. Cacahuate

0.500

Las elasticidades precio se basaron en información para México aún más deficiente, por lo que se concedió mayor confianza a estudios internacionales. ${ }^{35}$ Las elasticidades precio utilizadas fueron:

1. Maíz y trigo

$-0.10$

2. Chile verde y chile seco

3. Azúcar

4. Frijol, arroz, papa y garbanzo

$-0.30$

5. Jitomate

$-0.40$

6. Cebolla y ajo

$-0.20$

7. Pepino

$-0.60$

8. Camote

$-0.40$

9. Haba

$-0.40$

10. Avena, cebolla, maíz forrajero, sorgo, alfalfa y garbanzo

11. Cebada malta

12. Algodón

$-0.50$

13. Semilla de algodón, ajonjolí, linaza, cártamo, soya y cacahuate

14. Cacahuate

15. Fresa, piña, melón y sandía

$-2.00$

16. Tabaco

$-0.10$

${ }^{35}$ Debido a esta debilidad en la información, las pruebas de sensibilidad del modelo básico fueron realizadas con cambios en las elasticidades precio hasta $\pm 50 \%$ y se encontró que no se habían producido distorsiones significativas con cambios dentro de este rango. Se está llevando a cabo un nuevo estudio econométrico que dará nuevas estimaciones de las elasticidades precio e ingreso. 
Las proyecciones a 1976 que resultan de CHAC bajo estos supuestos, se presentan en el cuadro 7. Con el objeto de hacer algunas comparaciones gruesas, se presentan proyecciones alternativas. También se formuló una extrapolación de la tendencia a 1976 registrada de 1968 a 1972. Para 1968 se utilizó el promedio de los datos de tres años (1967, 1968 y 1969), con el objeto de suavizar el efecto de fluctuaciones a corto plazo; pero

\section{Cuadro 7}

CUltivos PRincipales: PROYeCCIONes alternativas del CONSUMO INTERNO APARENTE (miles de toneladas)

\begin{tabular}{|c|c|c|c|c|c|c|}
\hline \multirow[b]{2}{*}{ Gultivo } & \multirow[b]{2}{*}{$\begin{array}{c}\text { Datos reales } \\
\text { media } \\
\text { 1967-1969 }\end{array}$} & \multirow[b]{2}{*}{$1972^{\mathfrak{a} /}$} & \multicolumn{4}{|c|}{ Proyecoiones para 1976} \\
\hline & & & $\cos 0^{b}$ & CAM & $\begin{array}{l}\text { Elasticidad } \\
\text { ingreso d/ }\end{array}$ & $\begin{array}{l}\text { Krtrapola- } \\
\text { oisn do la } \\
\text { tendenoia } \\
\text { real } \\
1968-1972^{\circ}\end{array}$ \\
\hline $\begin{array}{l}\text { Caña de azdicar } \\
\text { Alfalfa verde } \\
\text { Mafz } \\
\text { Sorgo } \\
\text { Trigo } \\
\text { Frijol } \\
\text { Jitomato } \\
\text { Nrroz } \\
\text { Algodon } \\
\text { Cobolla } \\
\text { Sandia } \\
\text { Melón } \\
\text { Freas }\end{array}$ & $\begin{array}{rr}24 & 447.0 \\
7 & 753.7 \\
7 & 731.5 \\
2 & 065.0 \\
1 & 915.3 \\
791.4 \\
417.8 \\
356.9 \\
150.8 \\
138.5 \\
125.7 \\
117.9 \\
54.6\end{array}$ & $\begin{array}{rr}29 & 130.9 \\
9 & 900.0 \\
10 & 188.1 \\
2 & 803.0 \\
2 & 644.1 \\
921.3 \\
619.6 \\
\\
466.3 \\
191.0 \\
184.3 \\
196.4 \\
129.4 \\
\\
58.6\end{array}$ & $\begin{array}{rr}35 & 358.6 \\
11 & 925.2 \\
12 & 116.2 \\
2 & 515.4 \\
3 & 260.9 \\
1 & 279.1 \\
592.0 \\
563.9 \\
257.8 \\
254.6 \\
193.2 \\
192.0 \\
\\
82.0\end{array}$ & $\begin{array}{rr}38 & 582.7 \\
11 & 254.4 \\
10 & 226.8 \\
3 & 147.8 \\
2 & 759.9 \\
930.7 \\
619.1 \\
429.4 \\
337.0 \\
216.5 \\
220.6 \\
211.9 \\
81.9\end{array}$ & $\begin{array}{rl}37 & 082.0 \\
13 & 071.2 \\
12 & 583.2 \\
3 & 449.5 \\
3 & 117.3 \\
1 & 288.1 \\
656.3 \\
580.9 \\
248.8 \\
225.3 \\
204.6 \\
191.9 \\
88.9\end{array}$ & $\begin{array}{rr}34 & 712.2 \\
12 & 640.4 \\
12 & 022.0 \\
3 & 366.4 \\
3 & 209.9 \\
1 & 072.5 \\
918.9 \\
547.4 \\
241.9 \\
245.2 \\
306.9 \\
142.0 \\
62.9\end{array}$ \\
\hline
\end{tabular}

a Las cifras para este año son preliminares. En el caso de maíz, sorgo y arroz se utilizan datos preliminares de CoNASUPo para 1973; para el frijol, se utiliza la información del año de 1972 par considerar que la disminución en la "demanda real" en 1973, que resulta de esta información, no está de acuerdo a lo que sucedió en la realidad.

b Las proyecciones de chac se estimaron de la siguiente manera: Se calculó la tasa geométrica de crecimiento del consumo interno de 1968 a 1976 por cultivo, que surge de los resultados del modelo; posteriormente se aplicó esta tasa a las reales de 1968 (siempre se utilizó el promedio de los años 1967, 1968 y 1969), tomando en cuenta ocho años para estimar el consumo a 1976.

" CAM son las siglas del libro "Las características de la agricultura mexicana", de M. Rodríguez Cisneros y otros profesionistas destacados, publicado por el Banco de México, 1972. Para formular estas proyecciones, se estimaron elasticidades/ingreso, con los datos de la encuesta de ingresos y gastos familiares de 1968. En CHAC se consideraron las elasticidades derivadas de la encuesta de 1963.

"Las proyecciones en la columna encabezada por "elasticidad/ingreso", se hicie-on mediante un cálculo sencillo con las elasticidades ingreso consideradas en CHAC, al suponer que se registra $8 \%$ de crecimiento anual en el PIB. Estas proyecciones constituyen el método "naive" que permite comparar las proyecciones con métodos más sofisticados.

- La extrapolación de la tendencia real se estimó de la siguiente manera: Se aplicó para el período 1972-1976 la tasa geométrica de cambio registrada de 1968 a 1972. Es claro que ésta no es una proyección muy confiable, pero proporciona una base que permite enjuiciar en forma gruesa las otras proyecciones. 
para 1972 solamente se utilizaron las cifras de ese año. Por lo tanto, la calidad de estas extrapolaciones depende en gran medida de qué tan representativo fue el año de 1972.

Otra comparación que se presenta es con el conjunto de proyecciones formuladas por el Banco de México y publicadas recientemente en el libro Características de la agricultura mexicana (CAM). Para estas proyecciones se utilizaron estimaciones mucho más actualizadas de elasticidades ingreso, calculadas con base en la encuesta de ingresos y gastos familiares de 1968, realizada por esa Institución.

También se presenta una tercera comparación sugerida por los comentarios de la gráfica 1, que aparecen en la primera parte de este documento. Para la formulación de estas proyecciones se utilizaron las elasticidades ingreso consideradas en CHAC independientemente del modelo, pero junto con el supuesto de $8 \%$ de crecimiento en el PIB. Al comparar estas proyecciones con las de CHAC, es posible tener una idea de la cantidad en que las estructuras de demanda, elástica respecto al precio, y las estructuras de oferta, afectan las proyecciones.

Es clara la imposibilidad de hacer cualquier juicio absoluto de la calidad relativa de estas proyecciones. Sin embargo, puede obtenerse una idea aproximada, suponiendo en forma extrema que la extrapolación de la tendencia constituye la previsión correcta, y comparando las otras proyecciones en términos de la proximidad a las extrapolaciones de la tendencia. Cuando se sigue este método, las proyecciones de CHAC resultan ser "mejores" 36 para siete productos; las del estudio CAM resultan más adecuadas para tres productos y las del método de la elasticidad ingreso en cinco casos. Las proyecciónes de CHAC son menos adecuadas en tres casos, las de CAM en ocho y las del método de elasticidad ingreso en dos casos.

Estas comparaciones parecen estar en favor de CHAC de manera definitiva en contra de CAM, y sólo ligeramente en contra de la otra técnica. Esta comparación no prueba nada, pero permite afirmar que para la formulación de proyecciones, CHAC es probablemente mejor que técnicas alternativas. Dado que CHAC asocia precios, requerimientos de insumos, pautas regionales de producción, etc., con las proyecciones de demanda, estos resultados parecen indicar que cHAC podría ser utilizado eficientemente para la formulación de proyecciones de políticas agrícolas.

Una forma más adecuada de interpretar las proyecciones de cHAC, es asociarlas con los incrementos registrados en los precios. Si la meta es alcanzar para 1976 un nivel diferente de producción, las intervenciones en el mercado de productos, a través de cambios en los precios, podrían ser el camino adecuado para alcanzar los niveles de producción deseables. Sin embargo, los precios en CHAC deben ser interpretados cuidadosamente, ya que reflejan cambios en los precios relativos y no incluyen la tasa de inflación para la economía en general. Como los precios agrícolas son uno de los principales factores determinantes de la tasa

${ }^{30} \mathrm{O}$ iguales en calidad suponiendo que una diferencia de 0.1 miles de toneladas no es significativa a este nivel de produación. 
general de inflación, hay una falta de consistencia que no puede ser superada sin ligar formalmente a CHAC con algún modelo de la economía en general. Dadòs estos problemas en la interpretación de los resultados, la mejor forma de observar los precios de los productos que resultan de CHAC, es compararlos unos con otros y con el ritmo general de cambio en los precios relativos agrícolas (el cuadro 1 muestra que los precios agrícolas se elevan a un ritmo anual $2 \%$ más rápido que la tasa general de inflación). La predicción de CHAC por ejemplo, para el consumo de sorgo parece ser una de las predicciones más malas del modelo, con una estimación de 2815400 toneladas en 1976. Sin embargo, este dato está asociado, de acuerdo con el modelo, a un incremento en los precios relativos del sorgo de $2.2 \%$ anual, ritmo inferior que el del maíz $(2.3 \%)$, el de la cebada $(3.4 \%)$ o el de la alfalfa $(3.7 \%)$, que son los tres forrajes más importantes. Por tanto, el problema parece tener una inelasticidad relativa por el lado de la oferta de sorgo, por lo que sería necesario inducir un incremento más rápido en los precios para lograr que la producción de sorgo exceda la predicción de CHAC. ${ }^{37}$

\section{Patrones de producción}

Como se mencionó, CHAC es un modelo de equilibrio sectorial y su estructura analítica está orientada a establecer el equilibrio en el mercado de productos y en el mercado de factores. El equilibrio en el mercado de productos, para cada uno de los 33 considerados se alcanza a través de la igualdad entre la oferta que proviene de las diferentes regiones productoras y la demanda para cada uno de esos productos; definida por una función de demanda que establece las relaciones existentes entre cantidades consumidas y precios de los bienes.

El equilibrio en el mercado de factores se logra a través de la igualdad entre la demanda de todos los factores agrícolas, que se deriva de los requerimientos de la producción regional y la oferta de los mismos. La oferta de factores está definida en forma completamente inelástica, completamente elástica, o con pendiente intermedia, conforme al tipo de factor, como se explicó antes.

Por lo que se refiere a la oferta de productos agrícolas, la especificación en el modelo de 2345 funciones de producción para el total de las 20 regiones definidas de acuerdo a diversas tecnologías de producción, fechas de siembra, clases de tierra y tipos de riego, permite estimar la oferta total de cada producto y su integración regional, en función de las ventajas comparativas que presenta cada región. Estas ventajas entre regiones están definidas por: a) las cantidades relativas de los recursos disponibles, como hectáreas cultivables, productores agrícolas y agua de riego; $b$ ) por la calidad de los recursoș, asociada a la altitud, a las precipitaciones, a la composición de los suelos y a las condiciones genera-

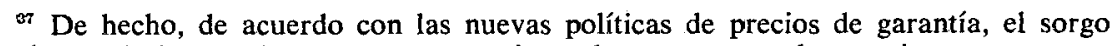
será uno de los productos con mayor ritmo de aumento en los precios. 
les del clima de cada zona productora, lo que se refleja en el nivel de los rendimientos y en la calidad de los productos agrícolas; y c) por la localización de cada una de las regiones en relación a los centros de consumo, lo que determina mayores o menores costos de transporte. ${ }^{38}$

Las soluciones estáticas del modelo permiten estimar los patrones de producción regional, en función de las ventajas comparativas que presenta cada zona productora e integrar la oferta de productos agrícolas por cultivo y por región que se deriva de una utilización eficiente de recursos, para compararla con la registrada en el mundo real.

$\mathrm{El}$ análisis de estática comparativa permite estimar el crecimiento necesario en la producción agrícola, total y por productos, para satisfacer los requerimientos del crecimiento de la población y del ingreso por habitante, ponderados por la elasticidad de ingreso de cada uno de los productos agrícolas. Este análisis también permite estimar el crecimiento de la producción agrícola regional para conformar la oferta sectorial. En CHAC, este crecimiento de la producción regional está determinado en función del crecimiento de la demanda sectorial y de'las ventajas comparativas regionales, ponderadas por aumentos diferenciales en la disponibilidad regional de los recursos agrícolas, como tierra, agua y mano de obra.

Con la solución para el período base, se calculó un índice de quantum con las cantidades y los precios endógenos del modelo, que supera en $12 \%$ al calculado con el volumen de producción nacional, de acuerdo a las estadísticas de la Secretaría de Agricultura y Ganadería (SAG). Esta diferencia de $12 \%$ está integrada por tres factores: el sesgo de agregación en el modelo, la falta de incorporación de algunas restricciones adicionales reales (ya sean económicas o no), y el hecho de que en el modelo se asignen los recursos agrícolas de manera más eficiente que en la realidad.

Dado que los tres factores proporcionan una discrepancia total de $12 \%$, parece que el sesgo por agregación que se establece en este tipo de modelos de programación lineal no constituye un problema serio.

Con el mismo criterio se formuló un índice de quantum de la producción agrícola en zonas temporaleras y tropicales que surge del modelo y se comparó con las estimaciones de la SAG, contenidas en el Plan Nacional 1968-69 para el mismo tipo de tierras. Los resultados muestran que el índice de producción estimado con los datos de CHAC era $4.63 \%$ inferior a las estimaciones de producción para esta área. Dado que las cifras realizadas representan el $93 \%$ respecto de lo programado en el promedio de los últimos seis años, se considera que el índice de producción de CHAC para zonas temporaleras es $3 \%$ superior a los niveles de producción obtenida.

En el cuadro 8 se presentan los volúmenes de producción para los 33 cultivos considerados que surgen del modelo, por cultivo y por región

3s Sobre el tratamiento de los costos de transportes en cHAC, véase Duloy y Norton (5). 
y los datos de la producción nacional de acuerdo a las estadísticas de la sAG para el promedio de 1967 a 1969. Cabe señalar que una de las principales discrepancias en los resultados del modelo, con los del mundo real, como es una producción menor de maíz $(17 \%)$ y mayor de trigo (39\%), se explica en función de las relaciones de sustitución que se plantean por el lado de la demanda dentro de un grupo de productos, como los granos. ${ }^{39}$ Esto significa que para satisfacer un determinado nivel de consumo de granos, es posible lograrlo a través de diversas proporciones entre maíz y trigo o de una combinación lineal entre ellas. Aunque este resultado del modelo puede ser mejorado al modificar las relaciones de sustitución en la demanda en chac, preferimos dejarlo así por dos razones: a) muestra que en el largo plazo se realizarían ahorros de recursos nacionales dando alicientes al consumo de productos trigueros; y b) tal y como está, CHAC parece capturar bien la tendencia real de producción de los granos (véanse el cuadro 7 y la nota $b$ del mismo).

La oferta que resulta de los 20 submodelos de producción de CHAC, se agregó en cinco grandes regiones para estimar los patrones de producción que ofrecen ventajas comparativas a nivel regional en las zonas de temporal y de riego. Destaca que la región noroeste, que incluye los distritos de riego del Río Colorado, Valle de Yaqui, el Fuerte, CuliacánHumaya y los otros distritos de riego de los estados de Baja California, Sonora y Sinaloa, tienen ventajas comparativas en la producción de cultivos de exportación, como el algodón, el jitomate, la sandía y algunas oleaginosas y granos. Las ventajas comparativas de estos productos se derivan en primer lugar de los elevados rendimientos que se obtienen, como resultados de las inversiones realizadas en mejorar la calidad de los recursos humanos mediante la creación de centros de investigación agrícola y de servicios de extensión agrícola. Los precios de los productos de exportación que reflejan la calidad del producto y menores costos de transporte, constituyen otro factor que determina las ventajas de esta región en la producción destinada a la exportación. Las relaciones entre tecnología de producción y disponibilidad de recursos, determina que esta zona, en donde la mano de obra es escasa y el grado de mecanización elevado, los cultivos más adecuados sean los que se pueden realizar en forma extensiva como el trigo, el cártamo y la soya.

La zona norte, que incluye los distritos de riego de Chihuahua, Coahuila, Nuevo León y Tamaulipas, ofrece ventajas en la producción de algodón y cacahuate (en Chihuahua) y algunas condiciones favorables para la producción de forrajes como alfalfa y sorgo y de granos como maíz y trigo. La región centro, que incluye todas las zonas de riego del centro y del sur del país, en las cuales la relación mano de obra/tierra es más elevada que en el norte y noroeste, ofrece ventajas en la producción de cultivos intensivos en el uso de mano de obra como las hortalizas (ajo, cebolla, chile, jitomate), los frutales de ciclo corto (fresa, melón sandía) y algunos forrajes como la alfalfa.

38 Véase Duloy y Norton (7). 
Cuadro 8

MODElo CHAC 1: YOLÚMENES DE PRODUCCIÓN POR CULTIVO Y POR REGIÓN EN EL PERÍODO BASE (toneladas)

\begin{tabular}{|c|c|c|c|c|c|c|c|}
\hline \multirow[b]{2}{*}{ Cultivos } & \multirow[b]{2}{*}{$\overline{\text { xyoroesto }}$} & \multicolumn{4}{|c|}{ Regiones } & \multirow[b]{2}{*}{ Total } & \multirow[b]{2}{*}{$\begin{array}{c}\text { Detos } \\
1967-1969\end{array}$} \\
\hline & & Dorto & Gentro & Tomporal & Tropical & & \\
\hline 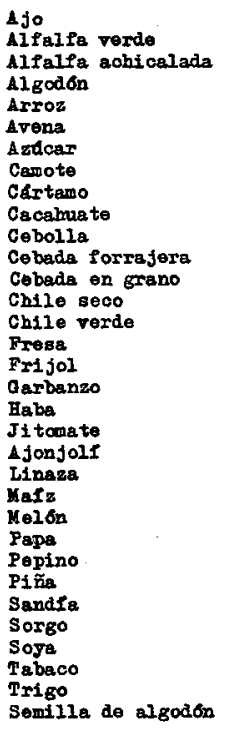 & 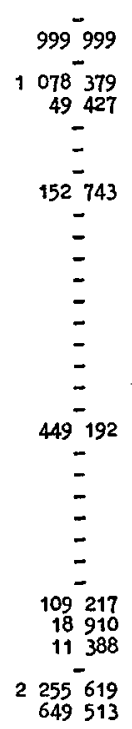 & 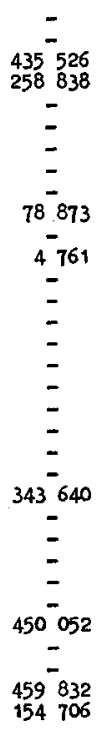 & 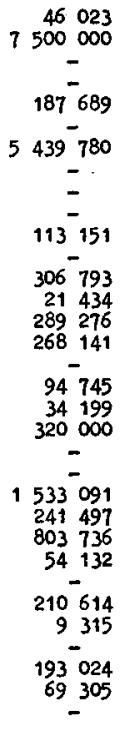 & $\begin{array}{c}1016846 \\
58 \quad 477 \\
66000 \\
343 \quad 158 \\
20 \quad 391 \\
1535028 \\
= \\
= \\
\overline{-} \\
1771578 \\
\overline{-} \\
100000 \\
83952\end{array}$ & 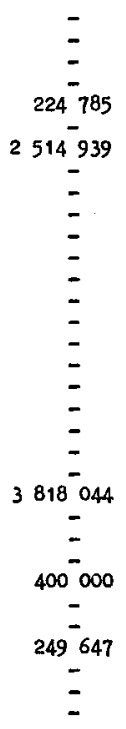 & 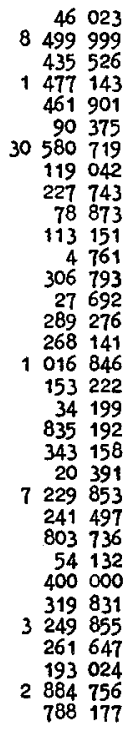 & 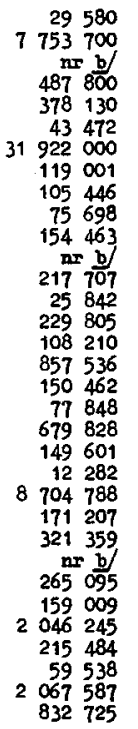 \\
\hline
\end{tabular}

"Datos proporcionados por la Dirección de Economía Agrícola, S.A.G.

b No reportado. 
De estos resultados también se aprecia que las zonas temporaleras ofrecen ventajas comparativas en la producción de granos como maíz, frijol y trigo, de algunas oleaginosas como ajonjolí, linaza, cártamo y de algunos forrajes como sorgo y avena a pesar de que los rendimientos son menores en zonas de temporal que en las de riego. Estas ventajas resultan de las posibilidades de utilización alternativa del suelo en las zonas de riego en comparación con las de temporal. Con el mismo criterio, las regiones tropicales muestran que los patrones adecuados de producción se orientan hacia el maíz, el arroz, la caña de azúcar, la soya y la piña.

Estos resultados constituyen algunos indicadores de los lineamientos de política a seguir a largó plazo en la localización de la producción agrícola. Dado que en el corto plazo existen inversiones realizadas en la instalación de plantas de procesamiento de productos agrícolas en las diferentes regiones, como es el caso de ingenios azucareros del noroeste y centro de la república, sería difícil promover en el corto plazo la introducción de estas pautas de producción. Sin embargo, estos resultados permiten derivar algunas sugerencias respecto a normas de producción en el largo plazo en función de ventajas comparativas tales como: a) Desplazar la producción de caña de azúcar de los distritos de riego del noroeste y del norte hacia las zonas tropicales, lo que requiere mayores inversiones en ingenios azucareros en estas regiones; $b$ ) En zonas temporales en donde hay abundancia de mano de obra, se debe ampliar la investigación básica para determinar los microclimas que permitan la producción de algodón, ya que por los elevados requerimientos de mano de obra de este cultivo en la época de la cosecha, sería eficiente aumentar los volúmenes producidos. Igualmente sería necesario ampliar la investigación local respecto a fechas de siembra, variedades de semilla de ciclo corto y curvas de respuesta a fertilizantes, en trigo, sorgo y varias oleaginosas (ajonjolí, cártamo y linaza). Los servicios de extensión agrícola, que constituyen el vehículo para difundir los resultados de la investigación, deben aumentarse en forma más que proporcional a los esfuerzos realizados en la investigación; c) En los distritos de riego de la región centro y sur, se debe mejorar la infraestructura de comercialización de las frutas y hortalizas que ofrecen ventajas comparativas en la producción. Estas inversiones corresponden a frigoríficos, a plantas clasificadoras y empacadoras de productos frescos, a industrias procesadoras de productos agropecuarios y a servicios de transporte refrigerado hacia los principales centros de consumo; $d$ ) En las regiones tropicales también se debe dar apoyo a la investigación y a la extensión agrícola, que permita incorporar a los patrones de producción tradicionales, algunos cultivos modernos como la soya.

El cuadro 9 y el cuadro 10 muestran la estructura de la producción regional en términos de participación porcentual, que surge de los resultados del modelo para el año base y la estructura productiva registrada en 1972. Destaca que la producción de cHAC está más especializada que 
la producción real, lo que se puede interpretar en el sentido de que los productores tratan de diversificar su producción como resultado de su aversión al riesgo. Sin embargo también refleja que los patrones históricos de producción no se adaptan rápidamente a la evolución de ventajas comparativas regionales.

Cuadro 9

MOdelo CHAC: ESTRUCTURA DE LA PRODUCCIÓN POR CULTIVO Y POR REGIÓN EN EL PERÍODO BASE

\begin{tabular}{|c|c|c|c|c|c|c|}
\hline \multirow{2}{*}{ Cultivos } & \multicolumn{5}{|c|}{ EOEIOAOA } & \multirow[b]{2}{*}{ Totel } \\
\hline & Noroeste & Norte & Centro & Temposal & Tropioal & \\
\hline \multirow{18}{*}{ 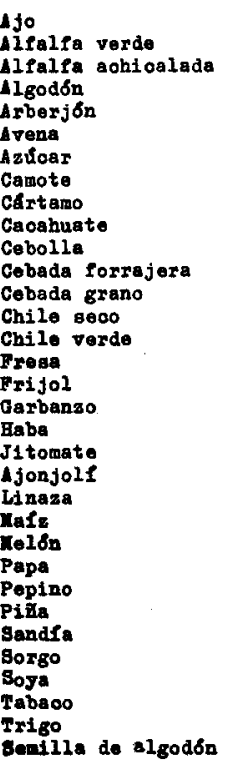 } & 11.7 & & $\begin{array}{r}100.0 \\
88.3\end{array}$ & & & $\begin{array}{l}100.0 \\
100.0\end{array}$ \\
\hline & 17.01 & 100.0 & & & & 100.0 \\
\hline & $\begin{array}{l}73.0 \\
10.7\end{array}$ & & 40.6 & 9.4 & 48.6 & $\begin{array}{l}100.0 \\
100,0\end{array}$ \\
\hline & & & 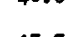 & 100.0 & 82,2 & 100.0 \\
\hline & & & 17.7 & 100.0 & & 100.0 \\
\hline & 67.0 & 1900 & & 32.9 & & 100.0 \\
\hline & & & 100.0 & & & 100.0 \\
\hline & & 1.5 & 98,4 & & & 1000 \\
\hline & & & $\begin{array}{r}90.4 \\
77.4 \\
100.0\end{array}$ & 22.5 & & $\begin{array}{l}100.0 \\
100.0\end{array}$ \\
\hline & & & 100.0 & 90 & & 200.0 \\
\hline & & & 64.8 & 38.2 & & $\begin{array}{l}100.0 \\
100.0\end{array}$ \\
\hline & 57.3 & & 38.3 & $\begin{array}{r}7.9 \\
100.0\end{array}$ & & $\begin{array}{l}700.0 \\
100.0 \\
100.0\end{array}$ \\
\hline & & 4.7 & & $\begin{array}{r}100.0 \\
21.2\end{array}$ & 52.8 & 100.0 \\
\hline & & 4.7 & $\begin{array}{r}51.2 \\
100.0 \\
100.0\end{array}$ & & & $\begin{array}{l}100.0 \\
100.0\end{array}$ \\
\hline & & & 100.0 & & 100,0 & 100.0 \\
\hline & 34.1 & 98 & 65.9 & $85 ?$ & & 100.0 \\
\hline & $\begin{array}{l}0.6 \\
4.3\end{array}$ & 13.8 & & & 95.7 & 100.0 \\
\hline & $\begin{array}{l}78.1 \\
88.5\end{array}$ & 15.9 & $\begin{array}{r}r 00.0 \\
2.4\end{array}$ & $\begin{array}{r}3.4 \\
11.5\end{array}$ & & $\begin{array}{l}100.0 \\
100.0 \\
100.0\end{array}$ \\
\hline
\end{tabular}

Los resultados del modelo para 1976 bajo los dos supuestos alternativos de crecimiento del PIB de $7 \%$ y de $8 \%$, de un aumento de $2 \%$ anual en la disponibilidad de la tierra cultivable, del agua de riego y de la mano de obra de los productores y de los supuestos de crecimiento en los rendimientos agrícolas, proporciona dos conjuntos de resultados respecto al crecimiento de la producción sectorial por grupos de cultivos (cuadro 11).

Destaca que el crecimiento de la producción de productos básicos (5.6\% y $6.1 \%$ ) y de féculas $(5.7 \%$ y $6.3 \%$ ) con los dos supuestos de crecimiento del PIB, es superior al crecimiento medio de la producción, lo que está determinado por el fuerte crecimiento de la población y la respuesta positiva del consumo interno a cambios en el ingreso de la po- 
Cuadro 10

ESTRUCTURA DE LA PRODUCCIÓN POR CULTIVO Y POR REGIÓN, 1972 (porcientos)

\begin{tabular}{|c|c|c|c|c|c|c|}
\hline \multirow{2}{*}{ Cult1vor } & \multicolumn{6}{|c|}{ B. $616 \mathrm{n}$} \\
\hline & Boreste & Worte & $\begin{array}{c}\text { Contro } y \\
\text { Sur }\end{array}$ & $\begin{array}{c}\text { Toupo- } \\
\text { ral }\end{array}$ & Tropioal & Total \\
\hline 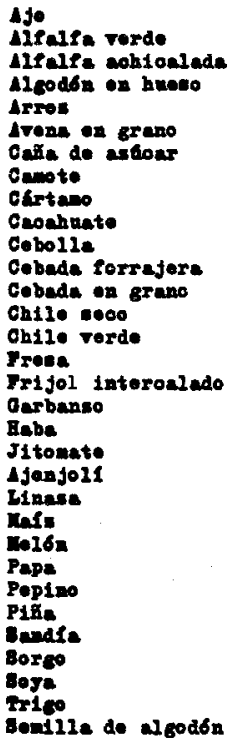 & $\begin{array}{r}6.3 \\
16.9 \\
- \\
56.9 \\
32.5 \\
0 \\
12.1 \\
0 \\
62.3 \\
1.4 \\
2.6 \\
0 \\
16.8 \\
0.3 \\
25.6 \\
0 \\
7.5 \\
19.7 \\
0 \\
39.1 \\
9.2 \\
58.2 \\
1.2 \\
8.0 \\
12.9 \\
65.0 \\
0 \\
9.0 \\
14.4 \\
87.0 \\
61.5 \\
56.2\end{array}$ & $\begin{array}{r}7.4 \\
14.8 \\
- \\
27.3 \\
0 \\
6.1 \\
5.3 \\
2.0 \\
2.6 \\
16.4 \\
21.4 \\
66.8 \\
1.6 \\
2.0 \\
9.3 \\
0 \\
1.2 \\
0 \\
0 \\
6.4 \\
2.0 \\
0 \\
4.2 \\
25.7 \\
12.3 \\
0 \\
0 \\
13.1 \\
26.7 \\
3.7 \\
16.4 \\
27.7\end{array}$ & $\begin{array}{r}82.0 \\
67.6 \\
- \\
6.5 \\
36.0 \\
2.6 \\
25.4 \\
58.2 \\
0.9 \\
24.4 \\
28.5 \\
25.5 \\
16.6 \\
71.8 \\
29.4 \\
99.9 \\
8.9 \\
2.5 \\
15.1 \\
40.6 \\
9.0 \\
0 \\
9.7 \\
55.8 \\
32.1 \\
31.9 \\
0 \\
48.3 \\
15.2 \\
0.9 \\
15.8 \\
6.3\end{array}$ & $\begin{array}{r}3.0 \\
0.3 \\
- \\
3.3 \\
8.3 \\
90.7 \\
11.7 \\
32.5 \\
32.2 \\
46.0 \\
46.2 \\
7.6 \\
54.6 \\
6.7 \\
7.6 \\
0 \\
59.6 \\
74.3 \\
69.2 \\
12.7 \\
61.5 \\
39.9 \\
58.3 \\
4.6 \\
29.7 \\
2.8 \\
36.2 \\
16.3 \\
38.0 \\
6.8 \\
5.8 \\
3.8\end{array}$ & $\begin{array}{r}9.1 \\
0.1 \\
- \\
5.7 \\
23.2 \\
0.3 \\
45.3 \\
7.1 \\
1.7 \\
19.6 \\
1.0 \\
0 \\
10.2 \\
18.9 \\
27.9 \\
0.1 \\
22.4 \\
3.3 \\
15.5 \\
1.0 \\
18.0 \\
1.8 \\
26.2 \\
5.6 \\
12.7 \\
0 \\
63.8 \\
13.0 \\
5.5 \\
1.4 \\
0.2 \\
5.8\end{array}$ & $\begin{array}{r}100.0 \\
100.0 \\
100.0 \\
100.0 \\
100.0 \\
100.0 \\
100.0 \\
100.0 \\
100.0 \\
100.0 \\
100.0 \\
100.0 \\
100.0 \\
100.0 \\
100.0 \\
100.0 \\
100.0 \\
100.0 \\
100.0 \\
100.0 \\
100.0 \\
100.0 \\
100.0 \\
100.0 \\
100.0 \\
100.0 \\
100.0 \\
100.0 \\
100.0 \\
100.0 \\
100.0\end{array}$ \\
\hline
\end{tabular}

Fuente: Dirección de Economía Agrícola,

blación. Este hecho, aunado a las perspectivas favorables para las exportaciones, explica el crecimiento de la producción de frutas $(4.8 \%$ y $6.1 \%$ ) y de hortalizas (5.5\% y $5.9 \%$ ). El bajo ritmo de aumento en los rendimientos por hectárea y las perspectivas poco alentadoras de las exportaciones agrícolas, determina que el crecimiento de las oleaginosas $(1.6 \%$ y $2.4 \%)$ y de los forrajes $(4.0 \%$ y $4.1 \%)$ sea inferior al crecimiento medio de la producción agrícola.

Por lo que se refiere a los patrones de producción en el tiempo, asociados a las ventajas comparativas regionales, constituyen un indicador de la localización que debería tener la producción en el futuro de acuerdo a los supuestos establecidos en la tasa de crecimiento del PIB, en los rendimientos por hectárea y en la disponibilidad de recursos agrícolas. El cuadro 12 muestra la tendencia cualitativa de la producción agrícola. Destaca que al aumentar el consumo de alimentos, las zonas temporaleras responden vigorosamente con aumentos en la producción de productos básicos (maíz y frijol) y oleaginosas. Estos aumentos corresponden a una 
Cuadro 11

Modelo Chac: TASa de CREcimiento ANUAL DE La PRODUCCión Por grupos DE PRODUCTOS, 1976

(porcientos)

\begin{tabular}{|c|c|c|c|c|c|}
\hline \multirow{2}{*}{$\begin{array}{l}\text { Grupo de } \\
\text { produotos }\end{array}$} & \multicolumn{3}{|c|}{ Inoxemento } & \multicolumn{2}{|c|}{ Taga do oreotmiento anual } \\
\hline & $1968=100$ & $1976-1977$ & $1976-1978$ & 7 & 8 \\
\hline $\begin{array}{l}\frac{\text { Blatoon }}{\text { Malr, frijol, trigo, }} \\
\text { arros }\end{array}$ & 100.0 & 154.0 & 160.0 & 5.6 & 6.1 \\
\hline 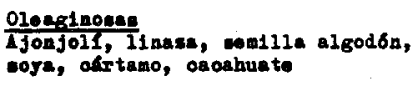 & 100.0 & $\$ 13.7$ & 121.1 & 1.6 & 2.4 \\
\hline $\begin{array}{l}\text { Porrajes } \\
\text { Sorgo, alfalea rorda, alfalfa } \\
\text { aohioalade, obbada forraje, } \\
\text { oobada grano, arena }\end{array}$ & 100.0 & 136.6 & 137.7 & 4.0 & 4.1 \\
\hline Futes & 100.0 & 145.9 & 160.1 & 4.8 & 6.1 \\
\hline$\frac{\text { PGoules }}{\text { Otwote, bubs, papa, garbanso }}$ & 100.0 & 155.7 & 163.2 & 5.7 & 6.3 \\
\hline 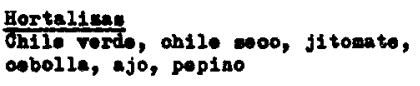 & 100.0 & 153.9 & 157.3 & 5.5 & 5.9 \\
\hline Andear & 100.0 & 132.0 & 453.2 & 3.5 & 3.9 \\
\hline Tebeoe & 100.0 & 106.1 & 123.9 & 0.8 & 2.7 \\
\hline$\Delta I_{\operatorname{sod} \mathrm{B}_{n}}$ & 100.0 & 140.2 & 149.6 & 4.3 & 5.2 \\
\hline Produooson totel & 100.0 & 144.4 & 152.0 & 4.7 & 8.4 \\
\hline
\end{tabular}

utilización mayor de las tierras marginales que se mantienen ociosas en la solución para el período base. Con aumentos en la demanda, estas áreas acentúan sus ventajas comparativas en la producción de algunos forrajes (avena, sorgo y garbanzo) y algodón.

En CHAC, los principales cambios cualitativos entre tiempo que registran los distritos de riego del centro se orientan al desplazamiento de la producción de ajo hacia el noroeste y de la de garbanzo y sorgo hacia las regiones temporaleras. Estos cambios indican que la productividad de la tierra en estas zonas es más alta en hortalizas y frutales, cultivos que registran los mayores aumentos.

En la zona noroeste los cambios cualitativos se enfocan hacia aumentos en la producción de hortalizas (jitomate y ajo) que ofrecen condiciones favorables para su comercio exterior, y hacia la producción de algunos cultivos extensivos como trigo y sorgo que por el impacto del cambio tecnológico acentúan sus características de adecuación a esta zona.

Los distritos de riego del noroeste muestran una tendencia a la especialización en la producción de forrajes y granos en tanto que disminuyen sus ventajas comparativas en la producción de algodón. Dada la utilización intensiva de la tierra en las zonas tropicales en el año base del análisis, los aumentos en producción no contemplan la incorporación de tierras marginales y están condicionados a los aumentos en los rendimientos por hectárea y en disponibilidades de recursos en estas zonas. 
Cuadro 12

Modelo CHAC: TENDENCIAS EN los PATRONES de PRoducción, 1968-1976"

\begin{tabular}{|c|c|c|c|c|c|}
\hline & Ioreoste & Norts & Contro & Toaporal & Troptoal \\
\hline 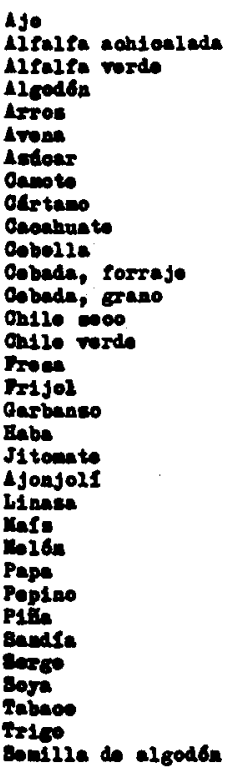 & $\begin{array}{r}+ \\
+ \\
+ \\
+\end{array}$ & + & $\begin{array}{l}- \\
+ \\
+ \\
+ \\
+ \\
+ \\
+ \\
+ \\
+ \\
+ \\
+ \\
+ \\
+ \\
+\end{array}$ & $\begin{array}{l}+ \\
+ \\
+ \\
+ \\
+\end{array}$ & + \\
\hline
\end{tabular}

$"++=$ Crecimiento mayor de $5 \%$ anual

$+=$ Crecimiento entre 0 y $5 \%$.

- =- Crecimiento igual o menor que cero

La tasa de crecimiento del $P I B=8 \%$.

VI. DISTRIBUCIÓN DE INGRESO Y DEMANDA DERIVADA PARA INSUMOS

\section{Distribución de ingreso sectorial}

En un modelo como CHAC, hay dos formas básicas de especificar la distribución del ingreso: $a$ ) incluir varios tamaños de predio; y b) especificar varias regiones productoras, lo que está orientado a captar distinciones importantes, como las existentes entre la agricultura de temporal y la de riego. En CHAC, los tamaños de predio están incluidos sólo en un submodelo, el del Bajío, y los niveles de ingreso asociados a los diferentes tamaños ya han sido presentados. ${ }^{40}$ Por lo tanto, como medidas de la distribución del ingreso sectorial, aquí sólo se presentan los resultados del ingreso regional.

* Véase Bassoco, Duloy, Norton y Winkelman (2). 
Al utilizar las medias de los ingresos regionales como puntos en una distribución de ingreso, se tiene la desventaja de que cada punto representa un grupo de ingresos individuales cuyo intervalo puede traslaparse con los intervalos de ingreso de otros. A pesar de esto, las estimaciones del ingreso regional son de interés, porque diferentes políticas pueden ser promovidas a nivel regional. Para adecuar los resultados de CHAC a la regionalización ampliamente aceptada del país, los veinte submodelos fueron agrupados en siete regiones: cinco que representan la agricultura de riego y dos a la de temporal. El cuadro 13 muestra los resultados de CHAC respecto al ingreso neto de los productores ${ }^{41}$ para las siete regiones en 1968. Hay que tener en cuenta que la cobertura del modelo excluye los predios que están dedicados principalmente a cultivos perennes y a ganadería. Sin embargo, el productor típico de cultivos anuales percibe una pequeña cantidad de ingresos adicionales de la producción de frutales y de la ganadería en pequeña escala. En CHAC no se incluyen estas fuentes de ingresos adicionales y por lo tanto se subestima un poco los niveles de ingreso de los productos.

\section{Cuadro 13}

Modelo chac: estimaciones de LA Distribución DEl INGREso aGRícola, 1968

\begin{tabular}{|c|c|c|c|c|c|c|}
\hline Eogen & $\begin{array}{l}\text { Ingrose } \\
\text { ne to anual } \\
\text { por prodios } \\
\text { (peoon) }\end{array}$ & $\begin{array}{l}\text { dero } \\
\text { prodiox }\end{array}$ & $\begin{array}{l}\text { Ingre so } \\
\text { aoumul ado } \\
\text { no to } \\
(\$)\end{array}$ & $\begin{array}{l}\text { Porolento } \\
\text { ocumuledo } \\
\text { do prodios }\end{array}$ & $\begin{array}{c}\text { Tamaño } \\
\text { modto } \\
\text { del pred10 } \\
\text { (he otirea) }\end{array}$ & $\begin{array}{l}\text { Ingrowo noto } \\
\text { por hootire } \\
\text { (ponos) }\end{array}$ \\
\hline 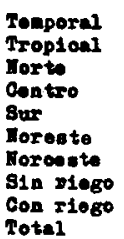 & $\begin{array}{rr}1 & 393 \\
3 & 886 \\
5 & 270 \\
8 & 825 \\
9 & 806 \\
10 & 530 \\
19 & 220 \\
2 & 226 \\
10 & 527 \\
4 & 140\end{array}$ & $\begin{array}{rr}1579 & 174 \\
792 & 217 \\
81 & 882 \\
407 & 665 \\
47 & 541 \\
40 & 396 \\
133 & 299 \\
1371 & 391 \\
2 & 710783 \\
310 & 781 \\
3082 & 174\end{array}$ & $\begin{array}{l}0.172 \\
0.413 \\
0.447 \\
0.729 \\
0.766 \\
0.799 \\
1.000 \\
0.413 \\
1.000\end{array}$ & $\begin{array}{l}0.512 \\
0.769 \\
0.796 \\
0.928 \\
0.943 \\
0.956 \\
1.000 \\
0.769 \\
1.000\end{array}$ & $\begin{array}{l}3.5 \\
2.9 \\
2.1 \\
2.4 \\
3.0 \\
6.5 \\
8.4 \\
3.3 \\
3.7 \\
3.4\end{array}$ & $\begin{array}{ll} & 398 \\
1 & 340 \\
2 & 510 \\
3 & 677 \\
3 & 269 \\
1 & 620 \\
2 & 280 \\
& 675 \\
2 & 845 \\
1 & 218\end{array}$ \\
\hline
\end{tabular}

El cuadro 13 muestra una fuerte discrepancia en los ingresos de los predios. En un extremo están los predios de temporal que constituyen $51.2 \%$ de la población (como se definió en el modelo) y perciben solamente $17.2 \%$ del ingreso y en el otro los predios de riego en el noroeste, que representan el $4.4 \%$ de la población y perciben el $20.1 \%$ del ingreso total. El agricultor medio en el noroeste con tierra de riego, percibe 13.8 veces más ingresos que el agricultor medio de temporal. Sin embargo, sólo menos de la mitad de esta diferencia se explica por una productividad mayor por unidad de tierra, ya que los predios de riego del noroeste son más del doble en tanaño que los predios de temporal.

t1 El ingreso neto de los productores se calcula como la diferencia entre el valor de las ventas a los precios endógenos del modelo y el valor de los insumos comprados. La mano de obra de los jornaleros se considera como una compra de insumos. 
En términos de productividad por hectárea, los predios con riego de la Meseta Central son más eficientes: $\$ 3677$ por hectárea en comparación con 2280 en el noroeste. Los predios de riego en el sur y en el norte también son más productivos por hectárea que los del noroeste. Parte de la explicación se encuentra en los patrones de producción, ya que la Meseta Central produce en proporción más frutas y hortalizas que cualquier otra región del país, el Sur produce tabaco y el Norte algodón. Sin embargo, en la Meseta Central, el productor utiliza menos insumos comprados y depende más de su propia mano de obra. Por lo tanto, existe una proporción mayor entre el ingreso neto y el ingreso bruto. Este hecho se puede apreciar al comparar el cuadro 13 y el cuadro 14. Con predios más pequeños es posible usar menos maquinaria y menos mano de obra de jornaleros.

Cuadro 14

Modelo CHAC: EMPleo Y VALOR DE LA PRODUCCión REgIONAL

\begin{tabular}{|c|c|c|c|c|c|c|}
\hline \multirow[b]{2}{*}{ Distrito } & \multicolumn{3}{|c|}{ Emploo } & \multicolumn{3}{|c|}{ Valor de le produoción } \\
\hline & $\begin{array}{l}\text { Por bootaros } \\
\text { oultivada a }\end{array}$ & $\begin{array}{c}\text { Por predio } \\
\text { b }\end{array}$ & $\begin{array}{l}\text { Por unidad } \\
\text { do ague of }\end{array}$ & $\begin{array}{l}\text { Por hoctáras } \\
\text { oul tivada d }\end{array}$ & For predto & $\begin{array}{l}\text { Par unided } \\
\text { de ague If }\end{array}$ \\
\hline $\begin{array}{l}\text { Yorcosets } \\
\text { Horts } \\
\text { Horeste } \\
\text { Contro } \\
\text { Sur } \\
\text { Temporal } \\
\text { Tropical } \\
\text { Ruego } \\
\text { To rlogo } \\
\text { Total }\end{array}$ & $\begin{array}{l}2.08 \\
2.07 \\
3.36 \\
4.52 \\
7.06 \\
1.11 \\
1.65 \\
3.58 \\
1.26 \\
1.85\end{array}$ & $\begin{array}{r}16.95 \\
10.50 \\
21.78 \\
11.06 \\
21.46 \\
3.88 \\
4.77 \\
13.41 \\
4.18 \\
6.31\end{array}$ & $\begin{array}{c}1.69 \\
2.48 \\
2.50 \\
7.90 \\
5.89 \\
- \\
- \\
3.42 \\
- \\
3.42\end{array}$ & $\begin{array}{ll}5 & 143 \\
4 & 120 \\
3 & 615 \\
4 & 652 \\
6 & 402 \\
1 & 377 \\
2 & 609 \\
4 & 811 \\
1 & 737 \\
2 & 517\end{array}$ & $\begin{array}{rr}41 & 904 \\
8 & 524 \\
23 & 467 \\
11 & 383 \\
19 & 436 \\
4 & 826 \\
7 & 527 \\
18 & 003 \\
5 & 729 \\
8 & 559\end{array}$ & $\begin{array}{ll}4 & 171 \\
2 & 009 \\
2 & 694 \\
8 & 129 \\
5 & 341 \\
= \\
\\
4 & \overline{600} \\
4 & \overline{600}\end{array}$ \\
\hline
\end{tabular}

a Meses-hombre/hectárea

b Meses-hombre/predio

c Meses-hombre/diez mil metros cúbicos

d Valor bruto en pesos/hectárea

- Valor bruto en pesos/predio

* Valor bruto en pesos/diez mil metros cúbicos

De los cuadros 13 y 14 se desprenden algunas consideraciones. En primer lugar, la proporción entre el ingreso neto y el ingreso bruto a nivel regional es la siguiente:

$\begin{array}{llll}\text { Temporal } & 0.29 & \text { Sur } & 0.50 \\ \text { Tropical } & 0.52 & \text { Noreste } & 0.45 \\ \text { Norte } & 0.62 & \text { Noreste } & 0.46 \\ \text { Centro } & 0.78 & & \end{array}$

En segundo lugar, la agricultura de riego como un todo, genera 4.7 veces más ingresos netos por predio en relación a la agricultura de temporal, 3.2 veces más ingresos brutos por hectárea y 2.8 veces más 
empleo. Estas cifras también revelan que un año-hombre ocupado genera 1.5 veces más ingreso neto con riego que sin riego. Las comparaciones de empleo están orientadas hacia la formulación de política. La incorporación del agua de riego, aumenta fuertemente la capacidad de absorción de mano de obra de la agricultura, aún cuando el predio típico de riego es más intensivo en el uso de maquinaria que el predio típico de temporal. Las fuentes de empleo adicional al introducir el riego son los mayores rendimientos por hectárea, lo que significa mayores requerimientos de mano de obra en la época de la cosecha, el doble cultivo y la posibilidad de introducir cultivos intensivos en el uso de mano de obra, como son las frutas y las hortalizas que además también requieren agua. En forma característica la producción de frutales y hortalizas requiere cuatro veces más empleo por hectárea que la producción de granos (maíz y trigo):

En cualquier sentido, ya sea en términos de volúmenes de producción, o de niveles de ingreso o de empleo, es evidente que el riego es un factor de primordial importancia. La desigualdad en la distribución del agua en los predios agrícolas es claramente la principal determinante de las desigualdades existentes en la distribución del ingreso.

La gráfica 4 muestra las curvas de Lorenz calculadas para estimar la distribución del ingreso en el sector en 1968 y 1976, con el supuesto de crecimiento en el PIB de $8 \%$. Las curvas son muy parecidas, con la excepción de que los grupos de ingreso más bajo parece ser que están mejorando en el transcurso del tiempo. Esto significa que los agricultores de temporal recibían $17.2 \%$ del total del ingreso de los productores en $1968,18.5 \%$ en 1976 con $7 \%$ de crecimiento y $19.2 \%$ en 1976 con $8 \%$ de crecimiento. En todos los casos los predios de temporal representan $51 \%$ del total.

Es claro que un ritmo mayor de crecimiento origina que la distribución del ingreso sectorial sea más uniforme. La razón de este hecho es la misma que para la existencia de una mayor elasticidad agregada de la oferta en las zonas de temporal. Esta razón es que los agricultores de temporal tienen más tierras marginales ociosas y por lo tanto tienen una respuesta mayor respecto a incentivos en el precio. Un ritmo de crecimiento más elevado significa términos de comercio más favorables, lo que induce a los agricultores de temporal a cultivar una proporción mayor de la tierra disponible. Los resultados son una mejoría en los niveles de ingreso. En sentido contrario, en el contexto de la economía mexicana, un ritmo menor de crecimiento origina un aumento de la desigualdad en la distribución del ingreso.

Por supuesto, estos resultados están condicionados a las hipótesis establecidas en relación al ritmo de aumento en los rendimientos y en la disponibilidad de recursos en cada región. Para presentar el problema de la distribución del ingreso en su forma más sencilla, se han usado los resultados de ingreso que surgen de las soluciones comentadas antes con el supuesto de igualdad en el ritmo de crecimiento en los 
Gráfica 4

MODELO CHAC: CURVAS DE LORENZ SOBRE LA DISTRIBUCIÓN DEL INGRESO SECTORIAL

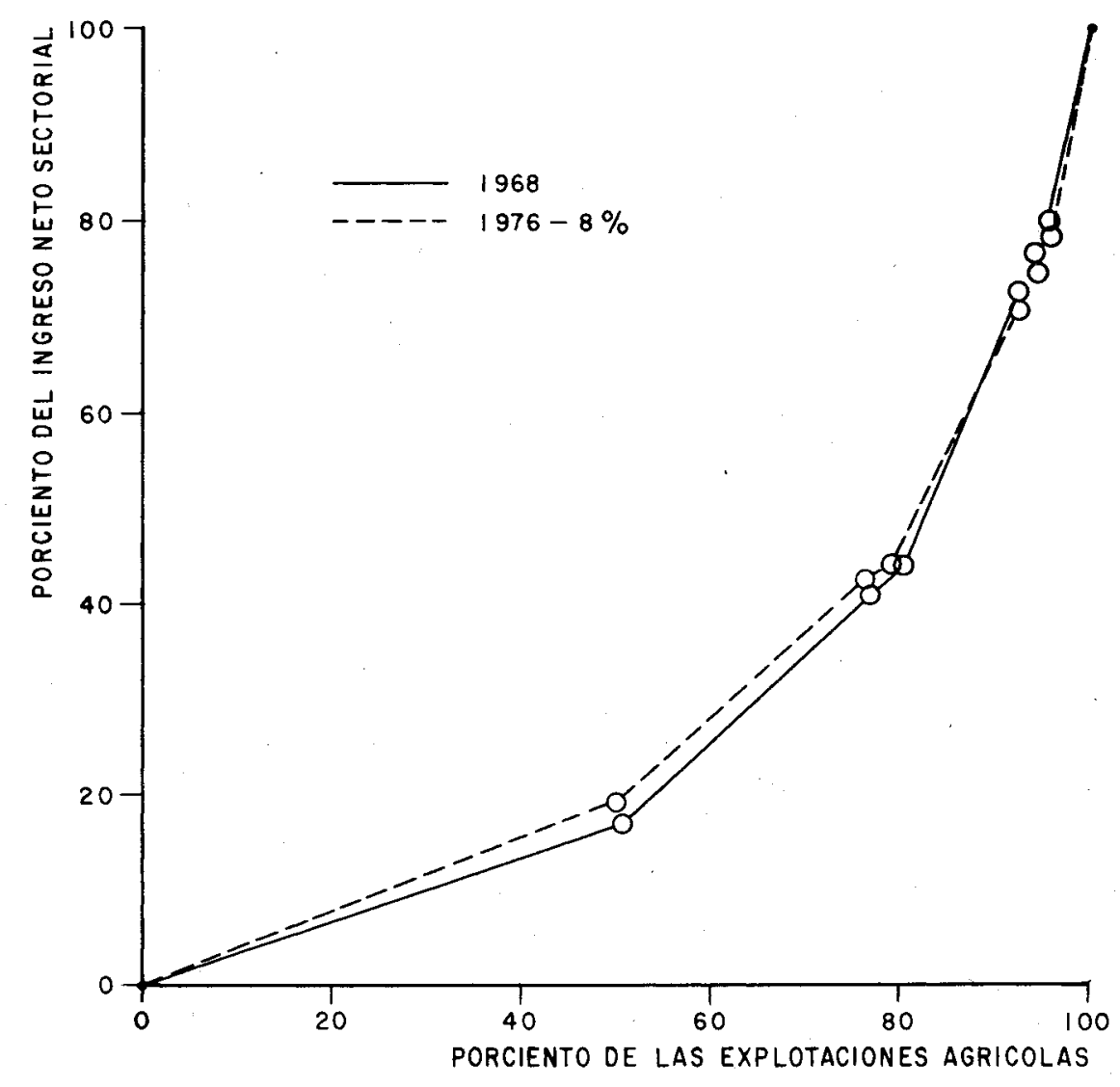


rendimientos y en la disponibilidad de recursos, tanto para la agricultura de riego como para la de temporal. Por desgracia la evidencia de las series de tiempo en este punto no es muy confiable, pero parece indicar que en forma gruesa ha existido igual ritmo de crecimiento en el progreso tecnológico y en el aumento en la disponibilidad de recursos, en ambos sistemas de producción agrícola.

Para continuar con este análisis más adelante, sería interesante modificar los supuestos establecidos en soluciones adicionales de CHAC. El enfoque se orientaría a evaluar cual sería el impacto en la distribución del ingreso, de un programa de investigación y extensión agrícola que favoreciera a las zonas de temporal.

\section{Patrones estacionales de empleo}

Como se mencionó en la primera sección de resultados macroeconómicos, es difícil evaluar la tasa de crecimiento del empleo sectorial sólo en términos del total de años-hombre ocupados. La estacionalidad es el punto fundamental del problema del empleo agrícola.

La gráfica 5 muestra el empleo sectorial mensual que resulta de las tres soluciones: la de 1968, la de 1976 con $7 \%$ de crecimiento y la de 1976 con $8 \%$. La primera característica que destaca es que el empleo en el sector agrícola tiene una elevada estacionalidad. En el mes crítico hay alrededor de cinco veces más empleo en comparación con el mes de menor empleo. Cada una de estas curvas estacionales, es una agregación de las curvas correspondientes para la agricultura de riego, la de temporal y la tropical. Ya que los cultivos, tanto de riego como tropicales generan demandas de mano de obra más o menos uniformes, en las zonas de temporal la estacionalidad es aún más marcada en la gráfica 5 .

La comparación de las tres curvas presentadas señala que el incremento en la demanda de empleo no se realiza de manera uniforme a lo largo de todos los meses. Por el contrario, el empleo aumenta más rápido en los meses críticos que en los de bajos niveles de empleo. Por lo tanto el grado de las variaciones estacionales se está volviendo cada vez más pronunciado.

Esto es una consecuencia inevitable de la tendencia señalada antes. La superficie cultivada aumenta más rápido en las regiones de temporal, ya que los incentivos del precio están incorporando tierras marginales al cultivo. Si bien el aumento de la superficie cultivada es uno de los objetivos de política agrícola, la estacionalidad creciente del empleo es una consecuencia desafortunada.

El cuadro 1 muestra que el total del empleo sectorial, medido en años-hombre ocupados crece $2.5 \%$ anual cuando el PIB crece $8 \%$ anual. Sin embargo, el empleo estable, medido a través de años-hombre ocupados en empleos que tienen duración de 10,11 o 12 meses al año, está creciendo solamente $2.0 \%$. En contraste, el empleo con estacionalidad 
Gráfica 5

EMPLEO ESTACIONAL

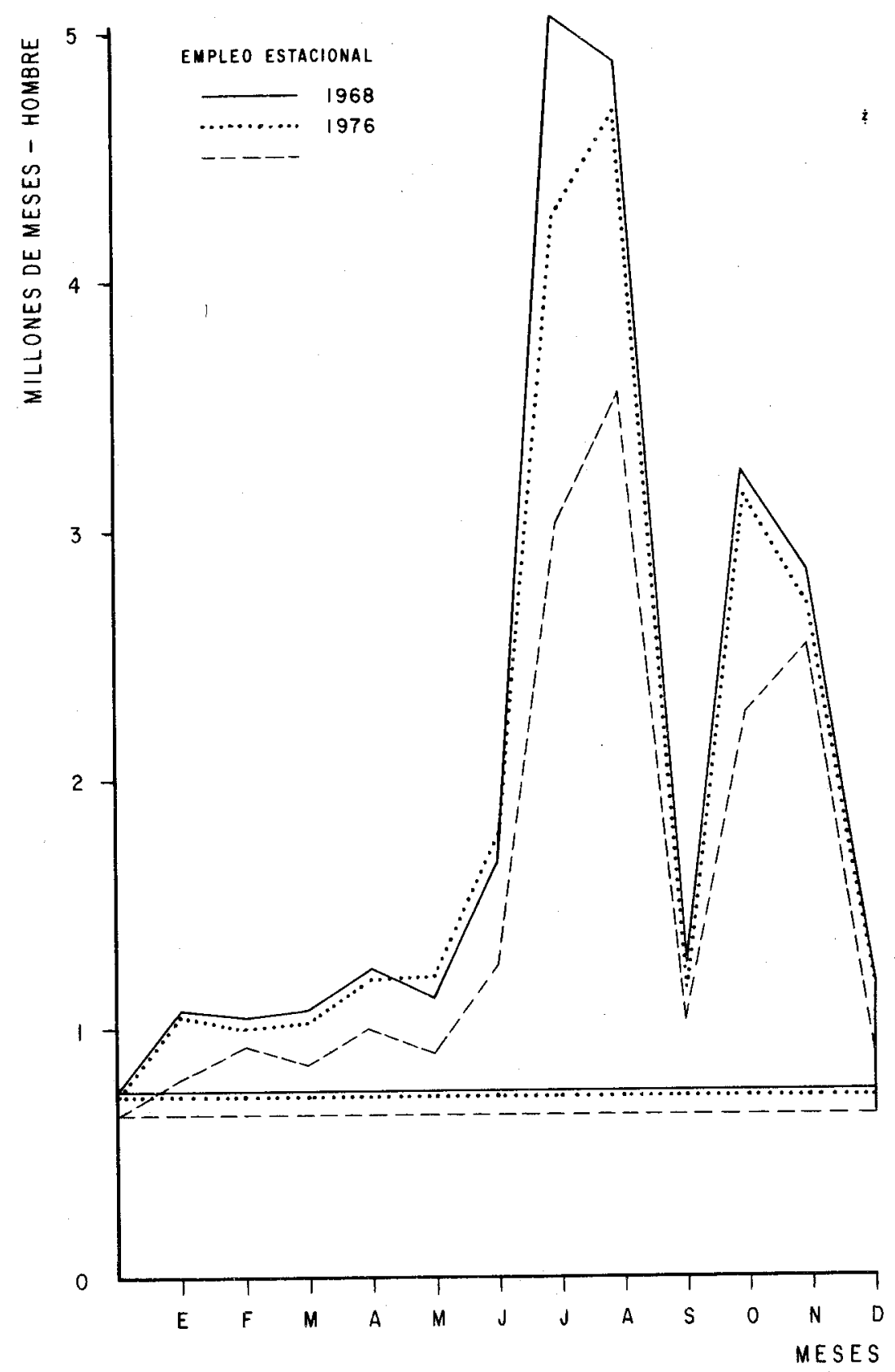


elevada crece $3.5 \%$ anual. El crecimiento más bajo se registra en los empleos que tienen una duración de 6 a 7 meses: $1.6 \%$ anual. Existen resultados similares disponibles para cada región y submodelo de cHAC. Aquí el enfoque es ofrecer sólo un ejemplo numérico de los resultados estacionales que surgen del modelo.

\section{Demanda derivada para otros insumos agrícolas}

Como en el caso del empleo, la utilización de insumos puede ser analizada de acuerdo a la clasificación regional establecida para las soluciones de CHAC. Aquí se presentan sólo los resultados agregados a nivel sectorial. El cuadro 15 muestra el porciento de respuesta que tiene la utilización de varios insumos en relación al porciento de cambio de la producción, de 1968 a 1976. Se puede apreciar que el crédito, las semillas mejoradas y las demandas de fertilizantes, crecen mucho más rápido que la producción misma. ${ }^{\text {f2 }}$ Esto significa que un crecimiento de $5 \%$ en la producción anual requiere un crecimiento de alrededor de $8 \%$ anual en la disponibilidad de crédito y en los fertilizantes y de $11 \%$ anual en las semillas mejoradas.

Cuadro 15

Modelo CHAC: elasticidades ReSPECTO A LA PRODUCCIÓN, 1968-1976

\begin{tabular}{|c|c|c|}
\hline & 74 & $8 \not 6$ \\
\hline $\begin{array}{l}\text { Ingreso geotorial } \\
\text { Cŕdito de arfo } \\
\text { Semilles mejorsdes } \\
\text { Produotos quimioos } \\
\text { Maquinaria agrioola } \\
\text { Animales de tracoion }\end{array}$ & $\begin{array}{l}1.063 \\
1.829 \\
2.319 \\
1.765 \\
0.894 \\
1.297\end{array}$ & $\begin{array}{l}1.056 \\
1.796 \\
2.185 \\
1.740 \\
1.000 \\
0.981\end{array}$ \\
\hline
\end{tabular}

Las técnicas intensivas en el uso de mano de obra, representadas por la utilización de fuerza de tracción animal, crecen más rápido que las técnicas intensivas en capital (que utilizan maquinaria), cuando el PIB crece al 7\% y en sentido contrario cuando el crecimiento del PIB es más elevado. Este hecho está relacionado probablemente con los precios agrícolas más altos en el segundo caso.

Por último, es interesante ver como responde la productividad marginal del agua de riego, a cambios en el crecimiento del PIB. Considerando $7 \%$ de crecimiento, cuando los precios agrícolas se elevan $1.5 \%$ anual en términos relativos, el valor del agua crece $1.8 \%$ anual. Sin embargo, al considerar $8 \%$ de crecimiento en el PIB y con precios que se elevan $2.0 \%$ anual, el valor del agua se eleva aún más rápido: $3.0 \%$ anual. Este tipo de cálculos son importantes para las evaluaciones beneficiocosto de los proyectos de riego.

* Cabe mencionar de nuevo que cHac es un modelo de sección transversal y no está basado en estimaciones de la tendencia histórica, para las relaciones que aparecen en el cuadro 15 . 


\section{REFERENCIAS BIBLIOGRÄFICAS}

1. L.M. Bassoco y Teresa Rendón, "The Technology Set and Data Base for CHAC", en L.M. Goreux y A.S. Manne (Comps), Mult-Level Planning: Case Studies in Mexico, Amsterdam, North-Holland Publishing Co., 1973.

2. Model of an Agricultural District," en Goreux y Manne, 1973.

3. J.R. Behrman, "Sectoral Elasticities of Substitution between Capital and Labor in a Developing Economy: Time Series Analysis in the Case of Postwar Chile", Econométrica, marzo de 1972.

4. Michael Bruno, "The Optimal Selection of Export-Promoting and Import-Substitution Projects", pp. 88-135 en Planning the External Sector: Techniques, Problems and Policies, Info: me del primer Seminario Interregional sobre Planificación del Desarrollo, 1967.

5. John H. Duloy y Roger D. Norton, "CHAC, A Programming Model of Mexican Agriculture", en Goreux y Manne, 1973.

6. - y R.D. Norton, "CHAC Results: Economic Alternatives for Mexican Agriculture," en Goreux y Manne, 1973.

7. - y R.D. Norton, "Competitive and Non competitive Demand Structures in Linear Programming," Trabajo de discusión Núm. 3, Development Research Center, I.B.R.D., agosto de 1973.

8. C.E. Ferguson, The Neoclassical Theory of Production and Distribution, Cambridge University Press, 1971.

9. Nicholas Gerogescu-Roegen, "Process Analysis and the Neoclassical Theory of Production", American Journal of Agricultural Economics, vol. 54, mayo de 1972. $W W$

10. - - ,Process in Farming versus Process in Manufacturing: A Problem of Balanced Development", Economic Problems of Agriculture in Industrial Societies, U. Papi y C. Nunn (Comps.), Macmillan, 1969.

11. John W. Mellor, The Economics of Agricultural Development, Cornell University Press, 1966. 